University of Rhode Island

DigitalCommons@URI

Open Access Master's Theses

1978

\title{
DEVELOPMENT OF A FLUORESCENT ASSAY FOR COLLAGENHETEROGENEITY USING MDPF-SDS-PAGE
}

Ronald Lee Goldberg

University of Rhode Island

Follow this and additional works at: https://digitalcommons.uri.edu/theses

\section{Recommended Citation}

Goldberg, Ronald Lee, "DEVELOPMENT OF A FLUORESCENT ASSAY FOR COLLAGENHETEROGENEITY USING MDPF-SDS-PAGE" (1978). Open Access Master's Theses. Paper 194.

https://digitalcommons.uri.edu/theses/194

This Thesis is brought to you for free and open access by DigitalCommons@URI. It has been accepted for inclusion in Open Access Master's Theses by an authorized administrator of DigitalCommons@URI. For more information, please contact digitalcommons-group@uri.edu. 


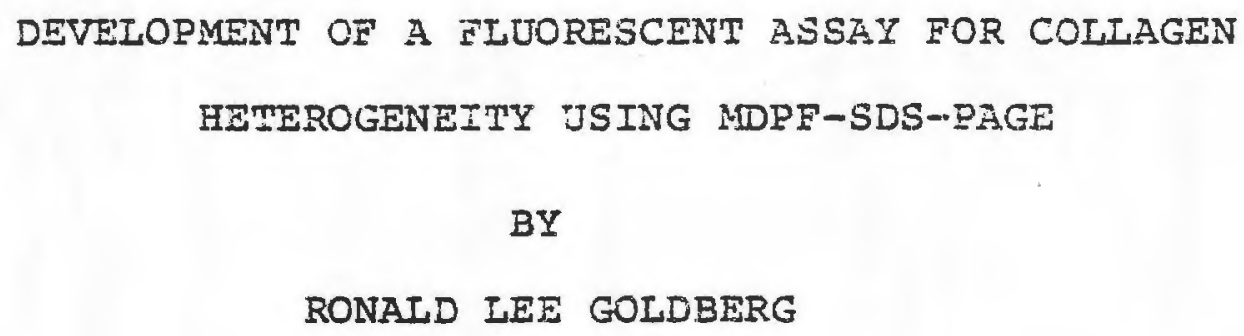

A THESIS SUBAITTED IN PARTIAI FULEILLMENT OF THE REQUIREMENTS FOR THE DEGREE

OF
MASTER OF SCIENCE
IN
PHARMACOIOGY AND TOXICOIOGY

INIVERSITY OF RHODE ISIAND

1978 


\section{MASTER OF SCIENCE THESIS}

OF

RONALD LEE GOLDBERG

\section{Approved :}

Thesis Committee

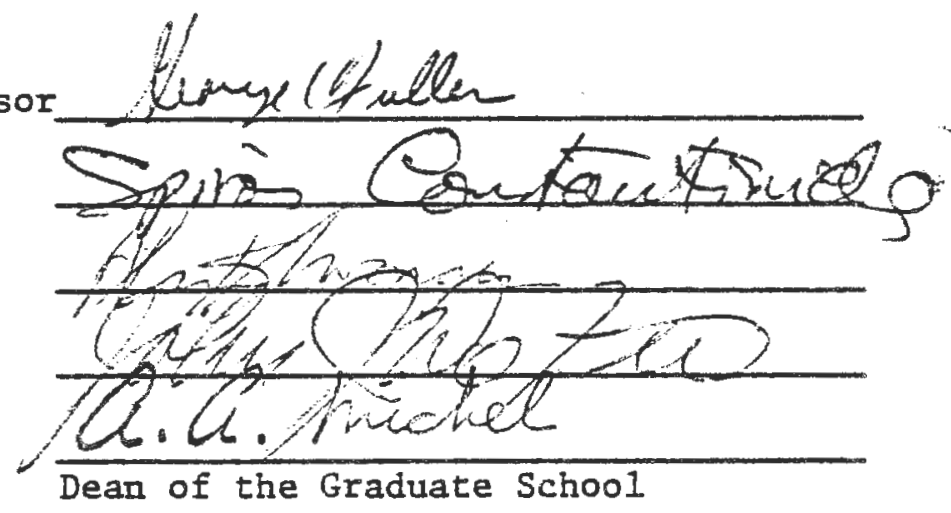

UNIVERSITY OF RHODE ISLAND

1978 


\section{ABSTRACT}

Purified coliagen were made fluorescent by coupling with 2-methoxy-2,4-dipheny $1-3(2 \mathrm{H})$-furanone, MDPF, and the Eluorescent products were separated by sodiun dodecyl sulfate-polyacrylamide gel electrophoresis, SDS-PAGE. The profiles of Coomassie blue stained and MDPF-labeled collagen bands on the gels were similar except for a slight increase in mobility with the MDPF coupled protein. The relationship between the amount and the area under the peaks recorded from fluorometric scanning of puxified $\alpha 1$ (I), $\alpha 2$ andal (III) was linear from $10^{-5} \mathrm{~g}$ to $10^{-8} \mathrm{~g}$. The standard curves for all three a chains were similar. Results from non-replicate determinations had an experimental error of

$\pm 6 \% \mathrm{SE}$. A mixed sample of cyanogen bromide (CB) peptides from type I and III collagen were quantitated by measuring the peak areas of known peptides from each type. The quantitation of collagen by the coupling of MDPF before electrophoresis is an improvement over staining with Coomassie blue after electrophoresis; since it provides a wider range of Iinearity, greater sensitivity, peak area independent of distance migration and less variability. The fluorescent method (MDPF-SDS-PAGE) also permits observation of bands during electrophoresis and quantitation immediately after electrophoresis. 


\section{ACKNOWLEDGEMENTS}

The author wishes to extend sincere appreciation and gratitude to Dr. George C. Fuller for his continuous understanding and support during this work.

Gratitude is extended to Dr. Fuller's research group and special thanks to Dr. Leonardo Galligani and Dr. David Parrott for their assistance.

To the author's parents a todah-rabo for their everlasting confidence and guidance.

This work was financialiy supported by $\mathrm{NIH}$ Grant HIl6904 and the American Heart Association grant awarded to Dr. George C. Fuller. 
TABLE OF CONTENTS

PAGE

ABSTRACT. . . . . . . . . . . . . . . . . . . . 1 . 1

TABIE OF CONTENTS .. . . . . . . . . . . . . . . . iii

LIST OF TABLES. . . . . . . . . . . . . . . . . . . . V

IIST OF FIGURES . . . . . . . . . . . . . . . . . vi vi

I. INTRODUCTION. . . . . . . . . . . . . . . 1

II. IITERATURE SURVEY . . . . . . . . . . . . . . 2

A. Collagen, structure, function, and biosynthesis . . . . . . . . . . . 2

B. Collagen heterogeneity. . . . . . . . 4

C. Collagen heterogeneity in pathophysiology. . . . . . . . . . . 6

D. Methods for quantitating collagen heterogeneity . . . . . . . . . . 8

E. Fluorescent labeled protein and its use in SDS-PAGE . . . . . . . . . . . 9

III. METHODS . . . . . . . . . . . . . . . 11

A. Purification. . . . . . . . . . 11

1. DSP . . . . . . . ...... 11

2. CMC . . . . . . . . . . . . 14

3. Molecular sieve chromatography. . . 16

B. Cyanogen bromide digastion. . . . . . I6

C. Coupling of MDPF to collagen. . . . . . 17

D. Electrophoresis procedures. . . . . . 13

1. Furtmayr and Timpl system. . . . . 17

2. Neville system........... 19

E. Staining and destaining - Coomassie blue. 20

F. Scanning procedure. . . . . . . . . 20

1. Optical density scanning. . . . . 20

2. pluorescent gel scanning. . ..... 21 
G. Photography. . . . . . . . . . . . $2 I$

H. Equations . . . . . . . . . . . . 22

1. Definitions for $8 T$ and 8 C. . . . . . 22

2. Conversion.......... . . 22

3. Statistics.......... . . 23

IV. RESULTS AND DISCUSSION . . . . . . . . . . 25

A. Characterization of MDPF-coliagen in

solution............... . . 25

B. Electrophoretic migration - effect of

MDPF ................... 29

C. Quantitation of a chains. . . . . . . 36

D. Type III collagen quantitation...... 4 II

E. Effect of distance migration on peak area. 44

F. Cyanogen bromide peptides from Type I and III collagen.... . . . . . . . . 47

V. CONCLUSIONS. . . . . . . . . . . . . . . 56

VI. REFERENCES . . . . . . . . . . . . . 58 


\section{IIST OF TABIES}

TABLE

PAGE

I Effect of MDPF on the Migration of collagen Components in SDS-PAGE. . . . . 36

II Comparison of Fluorometric and Densiometric Scanning of Type III Before and After 2-Mercaptoethanol. . . . . . . . 4 43

II Effect of Distance Migrated on Peak Area of MDPF-a1 (I) Collagen . . . . . . . . 46

IV Cyanogen Bromide Cleavage Products of Collagen a Chains. . . . . . . . . . 
LIST OF FIGURES

FIGURE

PAGE

I Flow Chart of Collagen Purification. . . . 13

2 CMC Gradient Hold System . . . . . . . . 15

3 MDPF Coupling Reaction.......... 18

4 Rate of Fluorogenic Reaction of MDPF with Collagen . . . . . . . . . . . . . . 27

5 Effect of Collagen/MDPF Ratio on Relative Fluorescence . . . . . . . . . . . . . 28

6 Photographic Records of Gels of Type I Collagen and Purified $\propto I$ (I) . . . . . . 30.

7 Densiometric and Fluorometric Scans of Type I Collagen and Purified $\alpha I(I)$. . . . $3 I$

8 Photographic Record of MDPF-Type I Collagen Electrophorsed by Furthmayr and Timpl

(1971) Method and the Nevilie (1971) Method 32

9 Photographic Record of Coomassie Blue Stained Gels of Collagen and MDPF-Collagen. 34

10 Standard Curve of MDPF-aI (I) versus RFI $x \mathrm{~mm} 37$

11 Standard Curve of MDPF-Collagen aChains versus RFI x mm . . . . . . . . . . 39

12 Densiometric and Fluorometric Scans of Type III Collagen Before and After Reduction. • . 42

13 Effect of Distance Migrated on the Fluorometric Scan of MDPF-aI(I). . . . . . . . 45

14 Fluorometric Gel Scan of MDPF-CB Peptides from Purified Collagen $\alpha$ Chains . . . . . . 49

15 Plot of the Relative Mobilities versus the Logarithm of Molecular Weight of CB Peptides from Purified a Chains. . . . . . 50

16 Standard Curve of the Ratio of $\mathrm{CB}$ Peptide Area from Type III and Type I Collagen versus the Percentage of Type III Collagen to Total Collagen Applied to the Gel. . . . . . . . 
17 Photographic Record of Gels of MDPF-CB Peptides from Type I and III Collagen. . . . 53

18 Standard Curve of the Peak Area of MDPF-CB Peptides versus the Amount of Type I and III Collagen Applied to Gel. . . . . . . . . 54 


\section{INTRODUCTION}

The abnormal accumulation of a specific collagen type may be a biochemical lesion that is an early diagnostic sign of pathology. To date, no good quantitative method exists for assaying micro-quantities of different collagen genetic types. The development of a micro-assay usable for the screening of routine biopsies for collagen heterogeneity change is necessary for assessing the role of various collagen types to pathological states. The use of tissue culture along with a sensitive method for studying collagen heterogeneity should provide a new way for the detection of biochemical lesions and for screening new drugs which may ameliorate the pathogenesis of connective tissue disease.

This thesis describes the development of a sensitive quantitative assay for collagen heterogeneity. This is the first useful application of the technique MDPF-SDS-PAGE for protein quantitation and the first use of MDPF-labeled collagen. 


\section{IITERATURE SURVEY}

Collagen, structure, function, and biosynthesis.

Collagen is the most abundant protein in the human body (Kivirikko and Risteli, 1976). Collagen fibrils are the fibrous connective tissue that provide structural rigiaity to the body. The structure and biosynthesis of collagen require study because collagen has important roles in growth, aging, wound healing, fibrosis, and vascular disease.

The molecule collagen is a trimer consisting of three helical polypeptide chains, $\alpha$ chains, each consisting of 1000 amino acids residues, a molecular weight of 95,000 daltons, and a left-handed twist, pitch $9 \AA^{\circ}$. The three chains are braided together with a right-handed twist making a rigid helical structure, pitch $2.9 \AA$, width $14 \AA$ and length $2800 \AA$ (Ramachandran and Ramakrishnan; Timpl, 1976). A short sequence at the amine and carboxy terminals of each $\alpha$ chain are non-helical. In the helical region, every third amino acid is glycine (Miller, 1976a); this is necessary for proper packing and possibly for hydrogen bond interaction within the helix (Ramachandran and Ramakrishnan, 1976). The imino acids proline (PRO) and hydroxyproline (HYP) occupy twenty-five percent of the collagen amino acid residues. Whereas in globular proteins imino aciàs serve to break helical conformations, 
in collagen these imino acids serve to stabilize the helical conformation (Ramachandran and Ramakrishnan, 1976). Collagen biosynthesis appears to invoive more extensive post-translational reactions than for any other proteins examined to date (Prockop, 1976). Collagen is first synthesized as a precursor molecule procollagen which is 40-50\% larger with globular register peptides at both the $\mathrm{NH}_{2}$ - and $\mathrm{COOH}$-terminals. At the $\mathrm{COOH}$ terminal, disulfide bonds Eorm bringing together three pro a chains for assembly as a triple helix (Byers et al., 1975). The growing nascent pro a chain is hydroxylated and glycosylated in the rough endoplasmic reticulum cisternae while still on the ribosomes. Some hydroxylation and glycosylation of procollagen is present in the smooth endoplasmic reticulum, however, no hydroxylation and glycosylation is found in the golgi complex, and these modifications cannot occur after helix formation (Kivirikko and RistelIi, 1976). Hydroxylation of proline, PRO $\rightarrow$ HYP, is essential for triple helix stability at $37^{\circ} \mathrm{C}$ (Prockop et al., 1976). The hydroxylation of Iysine, LSY $\rightarrow$ HLY, (Kivirikko and Prockop, 1972) is necessary for the stabilization of crosslinks, by the Amadori rearrangement (Bailey et al., 1974; Tanzer, 1976) and these hydroxyl groups are a site for glycosylation which affects fibre formation (Brownell and Veis, 1975).

Formation of the helix is essential for normal secretion of procollagen into the extracellular matrix (Olsen 
et al., 1975). The procollagen extensions are cleaved extracellularly by procollagen peptidases (Goldberg et al., 1975), which permits collagen aggregation and a fibre formation in the theorized quarter stagger arrangement (Miller, A., 1976). Another extracellular enzyme important in the processing of collagen is lyslyoxidase. This enzyme oxidatively deaminates certain IYS and HYS residues forming reactive aldehydes (allysine and hydroxyallysine). The aldehydes spontaneously react by the Schiff Base reaction with the $\varepsilon-\mathrm{NH}_{2}$ of a LYS and HIY from adjacent collagen molecules forming covalent intermolecular crosslinks. The crosslinks give tensile sirength to the fibre (Tanzer, 1973), and increase resistance to proteolysis by collagen, therefore decreasing turnover.

\section{Collagen heterogeneity}

Until the late 1960s, only one type of collagen molecule was known. It was found in bone, tendon, Iigament, and skin. This triple stranded collagen molecule consists of two identical chains and another which is geneticaliy distinct. The chains are designed $\alpha 1$ and $\alpha 2$ according to their elution order from carboxy methyl cellulose ion exchange column chromatography (CMC). In the early 1970s, a genetically distinct $\alpha$ chain was found in cartilage. This consisted of a chains that eluted from CMC only in the alposition. The amino acid composition and the 
cyanogen bromide mapping ( $C B$ ) peptide composition, demonstrated that this was a genetically distinct al molecule and therefore was designated as $\alpha I$ (II), the more ubiquitous $\propto I$ was designed as $\alpha I(I)$. Later, it was found that fetal skin has collagen CB peptides from another geneticalIy distinct $\alpha$ chain; this was designated as $\propto$ I(III). Basement membrane collagen was found to have another chain; this was designated as a I(IV). To date therefore, five genetically different $\alpha$ chains have been characterized for four different types of collagen (Kivirikko and Ristelei, 1976). Other putative $\alpha$ chains and collagen types have been found but they have not been well characterized (Benya et al., 1977; Little et al., 1977; Lichtenstein et al., 1976).

Type I, the most abundant collagen has a chain composition consisting of two $\alpha I$ (I) chains and an $\alpha 2$ chain; by common convention this would be written as $[\alpha I \text { (I) }]_{2} \alpha 2$. The a $I(I)$ chain has one dissaccharide moiety and the a 2 chain one monosaccharide and one disaccharide (Miller, 1976a). The complete amino acid composition sequence is known for a $I$ (I) (Piez, 1976).

Type II collagen has a chain composition of $[a I \text { (III) }]_{3}$ and is found predominantly in fetal tissue, blood vessels and to a lesser extent wherever Eype I is found (Miller, 1976a; Chung et al., 1974). In contrast to type I collagen, type III collagen contains more 4-hydroxyproline and it 
cystines which form intramolecular disulfide bonds that hold the collagen molecule as a trimer even under denaturing conditions. Antibodies to type III collagen have shown this type of collagen is associated with reticulin fiber (Gay et al., 1975). During the development of human skin, from fetal to adult, there is a decrease in type III collagen content and an increase in type I (Epstein, 1974; Chung and Miller, 1974). This is also true during the maturation of a wound from granulation tissue to a mature scar (Miller, E.J., 1976a). Type III collagen is found in arterial walls and may play an important role in vascular disease (McCullah and Balian, 1975).

Type IV collagen $[\alpha](I V)]_{3}$ is basement membrane collagen (Clark et al., 1976). In contrast to type I there is more hydroxylation of LYS and PRO (contains 3 hydroxyproline), more glycosylation and contains cystines. This collagen type has not been as well characterized as the other three. Breakdown of type IV collagen in basement membrane is an important step allowing metastasis to occur (Jaffe et al., 1976; Liotta et al., 1977).

\section{Collagen heterogeneity in pathophysiology}

There have been numerous reports of abnonmal accumulation of particular collagen types in disease processes (Lapiere and Nugens, 1976). In Ehlers Danlos syndrome type IV, there is an absence of type III sollagen in the extracellular matrix (Pope et al., 1975). Osteogenesis 
imperfacta is a deficiency of type I with an excess of type III collagen (Mueller et al., 1975). Kuttan et al. (1978) and Weiss et al. (1975) both found an elevation of type III collagen in synovial tissue of rheumatoid patients. In liver cirrhosis, Rodjkin et al. (1976) found an increase in both I and III type collagen but no difference in ratios. Kent et al. (1976) found first an increase in type III collagen followed by an increase in type I. Hypertropic scars and keloids have a high proportion of type III collagen (Bailey et al., 1975).

Vascular smooth muscles have been shown to increase total collagen synthesis in atherosclerosis (Ross and Gomsett, 1973; McCullogh and Ehrhart, 1974) and in hypertension (Ooshima et al., 1974). Type I and III collagen are found in the arterial wall. Only type III is found in regions immediately adjacnet to the endothelial layer but type I is the predominate extractable collagen in atheromatous plaques (McCullagh and Balian, 1975).

A problem with studying collagen heterogeneity is that unless extraction is complete, the recovery can give problems in ratio determinations. The results obtained are dependent upon the species used, the cell line, cell growth conditions, cell passages (or doublings), method of extraction and method of analysis. For example, using porcine medial smooth muscle cells, Scott et al. (1977) found type III in greater abundance than type I but Barnes 
(1976) found type I collagen as the more abundant type.

Methods for quantitating collagen heterogeneity

THere are numerous methods for studying collagen heterogeneity. To date, no one method has been shown to be par excellence. Antibodies to different types would be an ideal way to quantitate but no laboratory has so far developed a sensitive quantitative assay for collagen types based on antibodies. This may be due to the poor antigenecity of the collagen molecule and possibly cross reactions between types (Timpl, 1976). The column chromatography methods of ion exchange, CMC and DEAE-cellulose, and gel filtration, $A-5 M$ and $A-I 5 M$, can be used to separate different types of collagen pro a chains, $\alpha$ chains and CB peptides but these methods have the problem of being time-consuming, require large quantities; and result in variable recoveries.

Weber et al. (1977) reported that the sodium dodecyl sulfate polyacrylamide gel electrophoresis (SDS-PAGE) meth-od is the most applicable method for determining collagen types in routine biopsies. Scott et al. (1976a) quantitated type I collagen by $C B$ peptides with a Iinear range

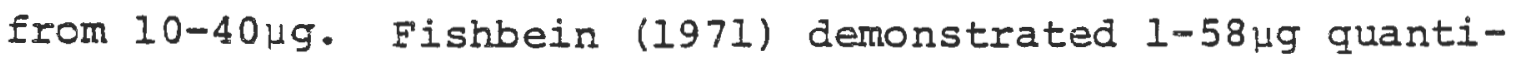
tation of the monomer $\alpha$-urease.

The most commonly used method for quantitating bands in SDS-PAGE is staining with Coomassie brilliant blue R-250. Other stains like fast green and amido black are used but coomassie blue is the most sensitive. The problem 
with quantitating stained bands in gels is as follows: dye cannot fully penetrate compacted protein bands (Fishbein, 1972) and the effect of alcohol on the selective removal of stain from protein bands has not been described in detail (Bertolini et al., 1976); deviation from Beer's Law (Gorovsky et al., 1970; Bennett and Scott, 1971); error found with densiometric measurements are 10-15\% (Fishbein, 1972 and Scott et al., 1976a); several hours to several days are necessary to have gels destained in order to do sensitive and quantitative gel scans; and the area beneath the curve is not independent of distance migrated (Fishbein, 1972). Distance migrated can affect sensitivity and linear range.

Fluorescent labeled protein and its use in SDS-PAGE Since the introduction of gel electrophoresis for protein separation there have been many attempts to improve sensitivity, linearity and shorten the time for analysis. Fluorescamine, Fluran, TM (Undenfreind et al..' 1972) which is not itself fluorescent but becomes intensely fluorescent when covalently coupled to primary amines offered many improvements over existing methods for the detection and quantitation of proteins (Bohlen et al.., 1973). Ragland et al. (1974) electrophoresed fluorescaminelabeled proteins and demonstrated quantitative fluorometric scanning in polyacrylamide gels immediately after electrophoresis. Pace et al. (1974) showed that migration of 
fluorescamine-labeled proteins is $\log$ linear to molecular weight by SDS-PAGE. The use of dansyl-labeled proteins has not been useful with SDS-PAGE because of the preiiminary treatment required to remove dansic acid and dansy amine (Eng and Parkes, 1974). In this procedure, the excess fluorescamine is rapidly converted to nonfluorescent products. With fluorescamine-labeled proteins, there is a postulated ring rearrangement to a nonfluorescent product that is more rapid in gels than in solution (Barger et al., 1976). The more recent use of 2-methoxy-2,4diphenyl-3(2H)-furanone (MDPF) (Weigle et al., 1973) as the fluor for detecting proteins in SDS-PAGE has advantages over fluorescamine in that the MDPF-labeled protein - fluorescence is stable and more intense. Barger et al. (1977) reported quantitative fiuorometric scans of MDPFlabeled proteins with linearity from $50-500 \mathrm{ng}$ and a sensitivity of I ng for some proteins (e.g., myoglobin). 
III. METHODS

\section{A. Purification}

1. DSP

The procedure adopted for the purification of collagen was that of Fujii and Kuhn (1975) as shown in Figure 1. Skin from a newborn calf was extracted in cold $0.05 \mathrm{M}$ Tris-HCl pH 7.5, IM NaCl for several days. The insoluble material was extracted in the cold, with $10 \%$ acetic acid for several more days. The remaining skin and extract were both lyopholized. Freeze-dried skin, $100 \mathrm{~g}$, was rehydrated in 251 of 0.18 acetic acid pH 2.0 (adjusted with HCl), $25.0 \mathrm{~g}$ pepsin was added slowly with. stirring, after $24 \mathrm{hr} 17.5 \mathrm{~g}$ pepsin was added for a further 24 hr digestion at room temperature.

The solubilized material was filtered through sintered glass wool. Sodium chloride crystals were added to the filtrate to give a final concentration of $0.9 \mathrm{M}$ sodium chloride; the mixture was allowed to stand overnight at $4^{\circ} \mathrm{C}$. The collagen that precipitated out was collected by continuous centrifugation at $15,000 \mathrm{xg}$ for $1 \mathrm{hr}$. The pellet was resuspended in $0.5 \mathrm{M}$ Tris- $\mathrm{HCl} \mathrm{pH} 7.5$, to inactivate the pepsin for four days, and then centrifuged at $35,000 \mathrm{xg}$ for $1 \mathrm{hr}$. The supernatant was lyopholized.

Differential salt precipitation (DSP) was performed to harvest the pepsin released Type I and Type III collagen. 
$30 \mathrm{~g}$ of the freeze-dried supernatant were dissolved in $10 \mathrm{I}$ of .05M Tris-HCl pH 7.5, IM sodium chloride. 4M sodium chloride was added to make a final salt solution of $1.7 \mathrm{M}$ sodiun chloride. The volume of $4 \mathrm{M} \mathrm{NaCl}$ added was determined by the following equation:

$$
c_{i} v_{i}+c_{a} v_{a}=C_{f}\left(v_{i}+v_{a}\right)
$$

where $C_{i}$ is the initial salt concentration (IM), $v_{i}$ is the initial volume $(101), C_{a}$ is the added concentration of salt (4M) and $C_{f}$ is the final desired salt concentration (1.7M). The equation is solved for $\mathrm{V}_{\mathrm{a}}$ which is the volume of $4 \mathrm{M}$ sodium chloride added. The solution was allowed to stand for $24 \mathrm{hr}$ and then centrifuged at 35,000Xg for $2 \mathrm{hr}$. The precipitant was washed by centrifugation three times in .05M Tris-HCl pH 7.5, 1.7M NaCl. The precipitant was resuspended in 18 acetic acid and dialyzed against $1 \%$ acetic acid, and then centrifuged at 55,000xg for $1 \mathrm{hr}$. The supernatant was Iyopholized and characterized as type III collagen by further purification gel electrophoresis; and cyanogen bromide peptide mapping. The salt concentration of the supernatant was then increased as described previously, again this time from $1.7 \mathrm{M}$ sodium chloride to 2.5M sodium chloride with $4 \mathrm{M}$ sodium chloride. The resulting precipitant was allowed to settle for $24 \mathrm{hr}$ and harvested by centrifugation at 35,000xg for $2 \mathrm{hr}$. The pellet was resuspended in iz acetic acid dialyzed against is acetic acid and then centrifuged at $55,000 \mathrm{xg} 1 \mathrm{hr}$. The 
Figure 1

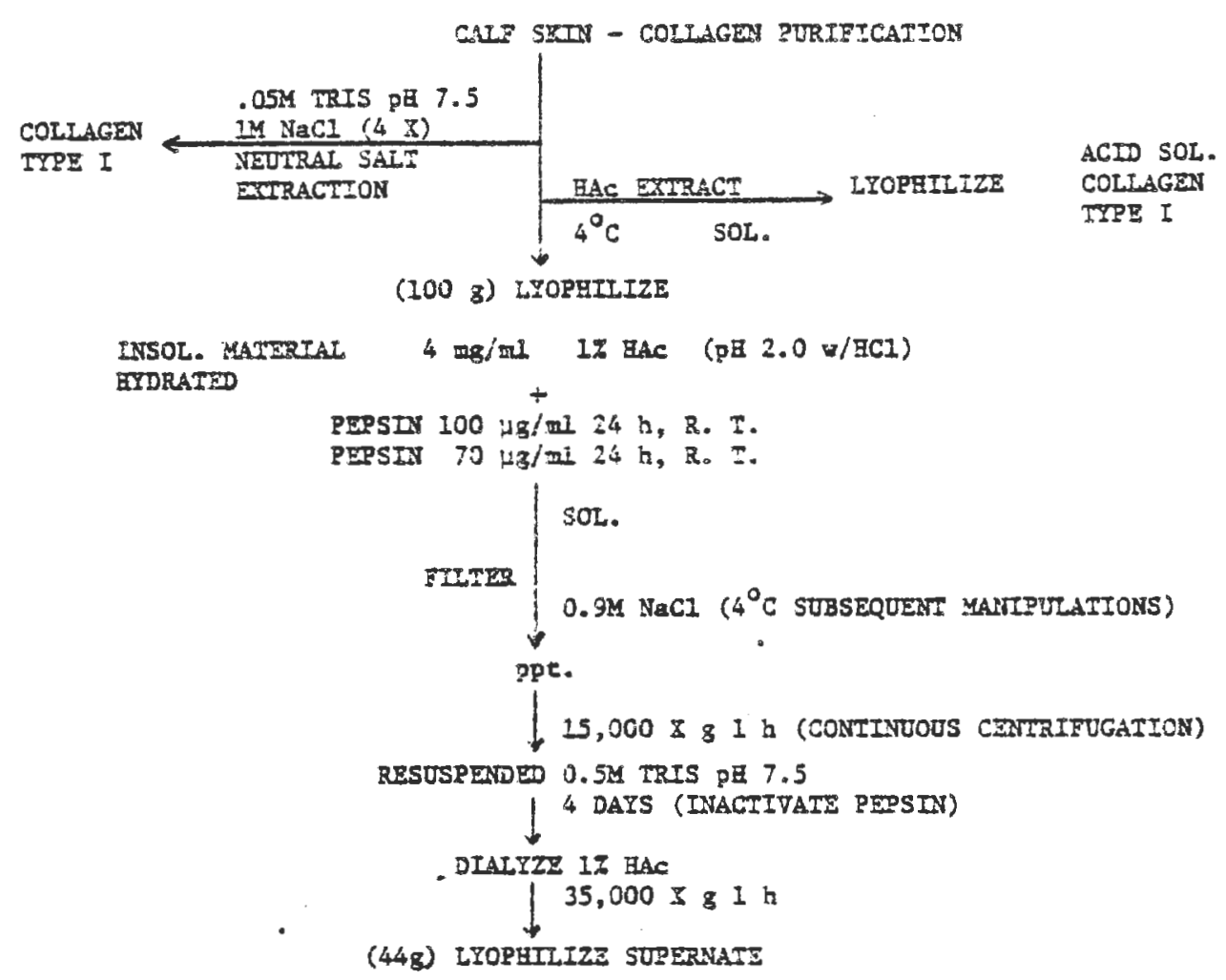

(30g) DS? $3 \mathrm{mg} / \mathrm{ml}$.OSM TRIS pH 7.5 iM $\mathrm{MaCl}$

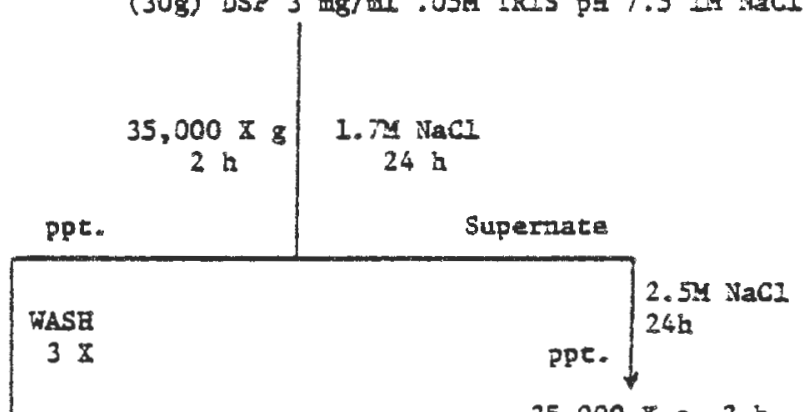

RESUSPEIDED 17 HAC

(5g) LYOPEITIZE SUPERNATE

DIALYZZ

TYPE III COLIAGEN
$35,000 \times 82 \mathrm{~h}$

RrSUSPENDE 17 EAC

DLALYZE

$\sqrt{55,000 \times g}+\mathrm{b}$

LTOPEIIIZE SUPERNATE (10g)

TIPE I COLIAGEN 
supernatant yielded $\log$ of Type I collagen. The collagen was characterized by further purification, gel electrophoresis, and cyanogen bromide peptiae mapping. 2. $\mathrm{CMC}$

Collagen obtained from DSP was further purified by carboxymethyicellulose chromatography (CMC) (Whatman CM-52) using the method described by Miller (1976). The column and buffers were maintained at $45^{\circ} \mathrm{C}$ throughout the experiment. This ensures that the collagen remains denatured. The CMC column dimensions were $2.5 \times 12.0 \mathrm{~cm}$. The starting buffer was $0.06 \mathrm{M}$ sodium acetate $\mathrm{pH} 4.8$ and the limiting buffer was $0.06 \mathrm{M}$ sodium acetate $\mathrm{pH} 4.8,0.1 \mathrm{M} \mathrm{NaCl}$. All buffers were heated and deareated immediateiy prior to use. The sample for chromatography, $200 \mathrm{mg}$ collagen $20 \mathrm{ml}$ starting buffer plus $2 \mathrm{~g}$ urea, was heat denatured at $56^{\circ} \mathrm{C}$ for 15 minutes and then pumped onto the column. The flow rate was set at $200 \mathrm{ml} / \mathrm{hr}$. The linear salt gradient, developed by a constant leveling device, was monitored by a Pharmacia Refractive Index monitor (RI). The eiuted collagen components were monitored at $206 \mathrm{~nm}$ using a Uvicord III Spectrophotometer. Chromatograms from 2.5 DSP and 1.7 DSP were similar to the ones reported by Fujii and Kuhn (1975) and Miller (1976).

Improved purifications of $\alpha I$ (I) and $\alpha 2$ were obtained by using a gradient hold system (Figure 2). A discontinuous 


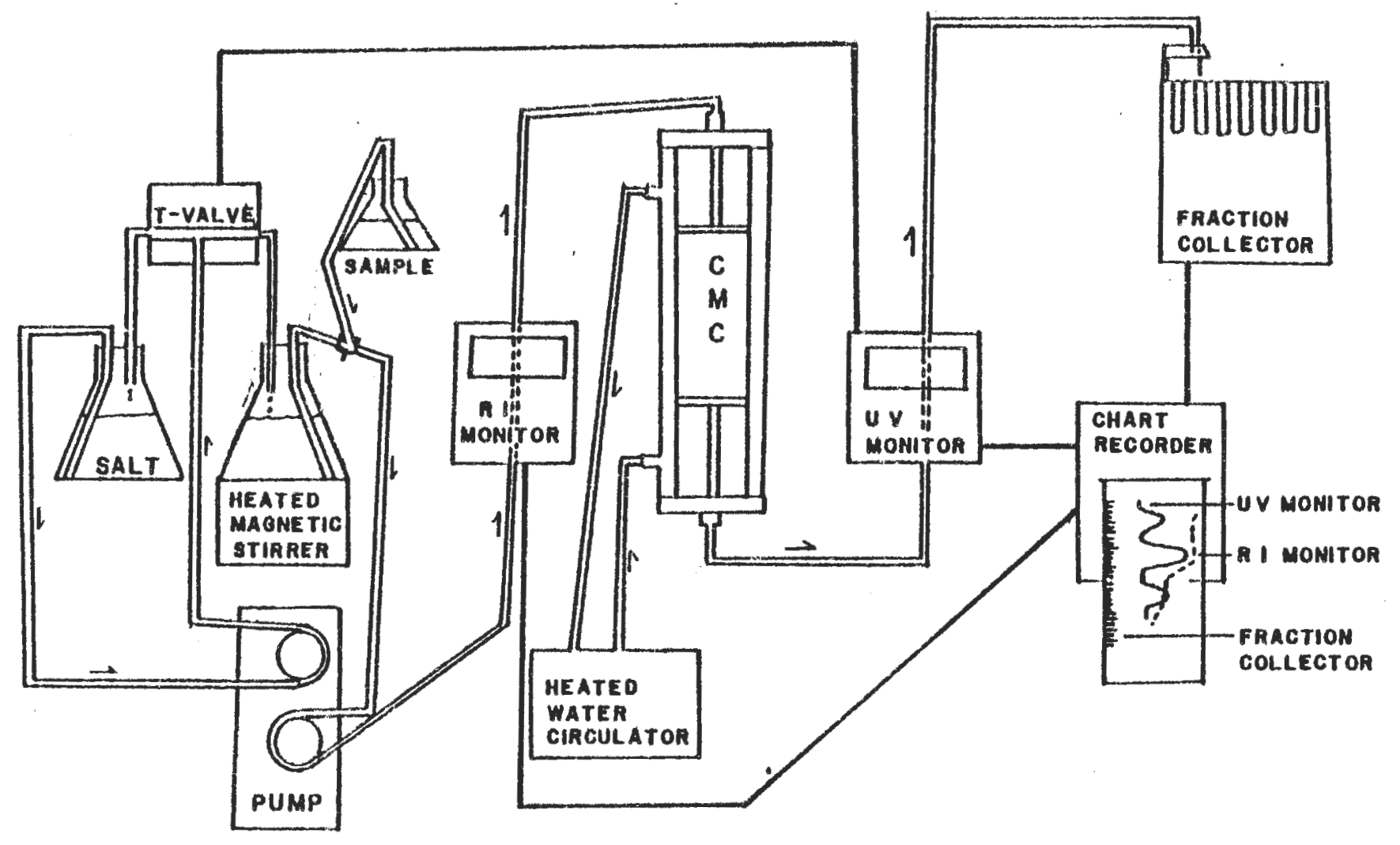

\section{CMC GRADIENT HOLD SYSTEM}

Fig. 2. Carbóxymethylcellulose chromatography was performed by a modification of Miller (1976b) method. A refractive index meter monitored the salt concentration and a spectrophotometer, $\lambda=206 \mathrm{~nm}$, monitored the eluted protein (collagen). When the absorbance, as measured by the U.V. monitor exceeded a set level the T-valve closed the channel to the gradient and opened the channel for recirculating the salt solution. When the peak cleared, and the absorbance fell below the set level, the T-valve opened the channel to the gradient and the linear salt gradient: continued. 
salt gradient was formed when a LKB Ultrograd valve closed in response to a protein peak sensed by the Uvicord III. This automatically held the salt concentration constant until the peak was cleared. The fractions containing the chains were desalted by dialysis and then freeze-dried. 3. Molecular sieve chromatography

The collagen components obtained from CMC chromatography were further purified by gel filtration according to the procedure of Fujii and Kuhn (1975). A $2.5 \times 20$ $\mathrm{cm}$ diameter column was packed with first $100 \mathrm{~cm}$ of Biogel A-I5M (200-400 mesh Bio Rad Laboratories) and then $18 \mathrm{~cm}$ of Bio Gel A-5M (200-400 mesh Bio Rad Laboratories). The elution buffer was $0.05 \mathrm{M}$ Tris-HCl pH 7.5, $1 \mathrm{M} \mathrm{CaCl}_{2}$. - Collagen, $30 \mathrm{mg}$, was dissolved in $3 \mathrm{ml}$ of $8 \mathrm{M}$ urea then 0.6 $\mathrm{M} \mathrm{CaCl}_{2}, 0.03 \mathrm{M}$ Tris $\mathrm{HCl} \mathrm{pH} 7.5$, heated at $56^{\circ} \mathrm{C}$ for 10 minutes and then applied to the column. A hydrostatic pressure of $30 \mathrm{~cm}$ gave a flow rate of $12 \mathrm{ml} / \mathrm{hr}$. The peak fractions were desalted by dialysis and then lyophilized. B.Cyanogen Bromide Digestion

Purified collagen types and o chains $(2-8 \mathrm{mg} / \mathrm{ml})$ were dissolved in $70 \%$ Formic Acid flushed with nitrogen. Cyanogen bromide, CNBr (Eastman) solutions $10 \mathrm{mg} / 1 \mathrm{ml}$ in $70 \%$ formic acid were added $I: I(v / v)$ to collagen solutions. These reaction mixtures were stirred at room temperature under nitrogen for $4 \mathrm{hr}$. The reaction was terminated by diluting tenfold with distilled water followed by lyophilization (Scott and Veiss, 1976). 
C. Coupling of MDPF to Collagen

The MDPF was dissolved in acetone at $2 \mathrm{mg} / \mathrm{ml}$. Two methods were used for MDPF coupling to collagen. In the first collagen was dissolved at room temperature in $0.01 \mathrm{M}$ phosphate $\mathrm{pH} 7.2,2 \mathrm{M}$ urea, $1 \% \mathrm{SDS}$ and $10 \%$ sucrose. The pH was raised with 0.02 volumes $2 \mathrm{~N} \mathrm{NaOH,} \mathrm{then} 0.2$ volumes of the MDPF solution were added with mixing. After 5 minutes the $\mathrm{pH}$ was returned to neutrality with 0.02 volumes $2 \mathrm{~N}$ HCl. In the second procedure collagen was dissolved at roorn temperature in $0.1 \mathrm{M} \mathrm{NaHCO}_{3} \mathrm{pH} 10.0,1 \%$ SDS and $10 \%$ sucrose. Then 0.2 volumes of the MDPF solution were added with mixing. After 5 minutes, 0.1 volume of a solution of $5 \%$ Tris, $2.5 \%$ boric acid and $1 \%$ SDS was added. The rate of the fluorogenic reaction is strongly pH dependent, but the resultant fluorescence is independent over a wide $\mathrm{pH}$ change of ranges (Weigle et al., 1973). Figure 3 shows the reaction between a MDPF moiecule and a $\varepsilon-\mathrm{NH}_{2}$ of $a$ Iysyl residue. There are approximately 35 IYS and HYL and one amino terminal in a collagen a chain, therefore most of the fluorescence is due to LYS and HYL. The pH was decreased after coupling, because at alkaline pH during heat denaturation, the disulfide bonds of type III collagen are broken.

D. Electrophoresis Procedures

1. Furthmayr and Timpl System

The samples were electrophoresed in a continuous buffer system as described by Furthmayr and Timpl (1971) 


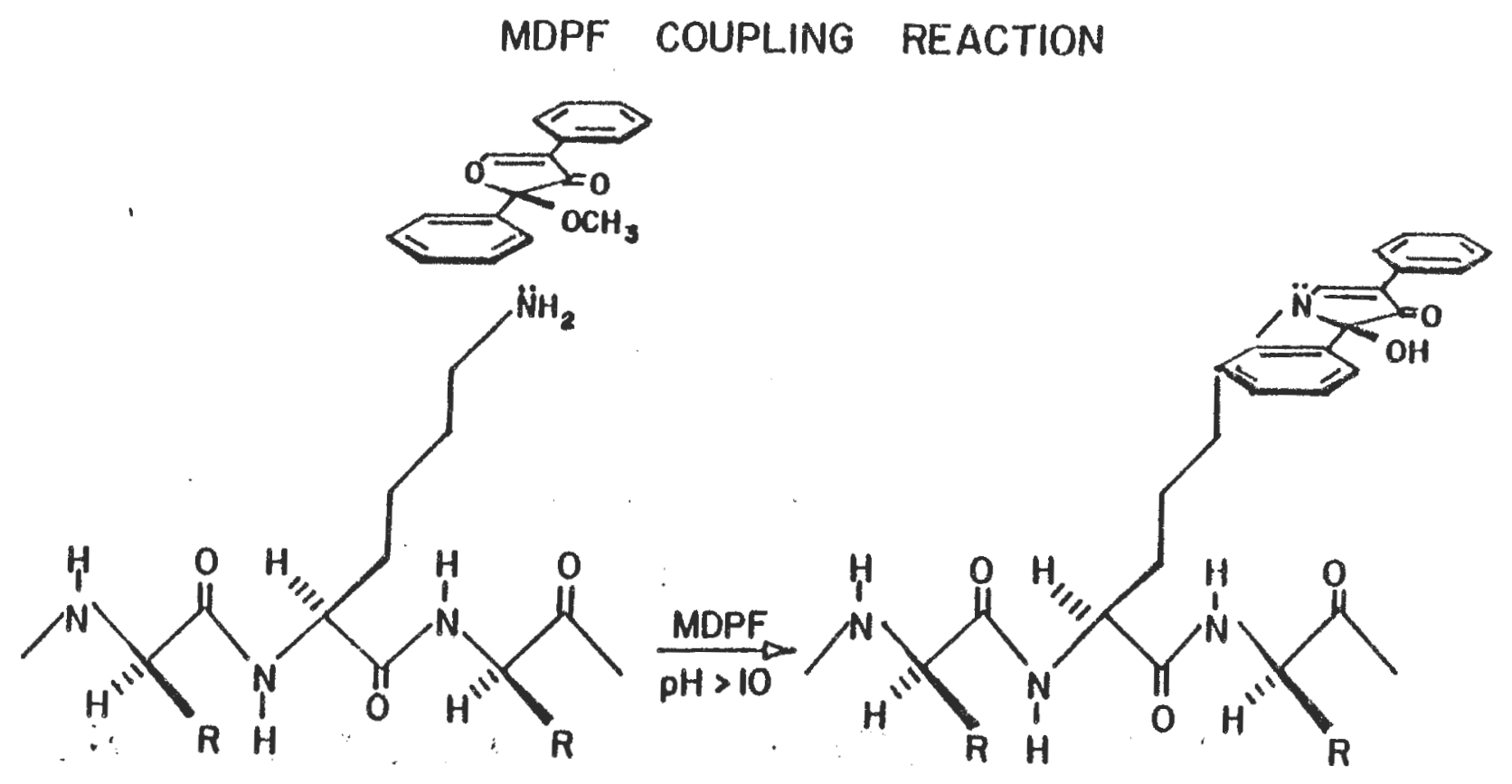

MDPF $=2-M E T H O X Y-2,4-D I P H E N Y L-3-(2 H)-F U R A N O N E$

Fig. 3. There is a nucleophilic attack by the E-amine of a lysyl residue on the number 2 carbon of the furanone ring. The ring opens with a loss of the methyl group. The oxygen in the furanone ring and the hydrogens of the amine combine to form water. The ring closes around the nitrogen. This covalently coupled product is fluorescent with excitation $390 \mathrm{~nm}$, emission $480 \mathrm{~nm}$. A slower hydrolysis reaction occurs with the uncoupled MDPF, in which the 2-methoxy becomes 2-hydroxyl, this is a non-fluorescent product. 
except $0.05 \mathrm{M}$ phosphate $\mathrm{pH} 7.2$ and $0.1 \%$ SDS was used as the electrophoresis buffer. The polyacrylamide gels, $5 \mathrm{~mm} \times 60$ $\mathrm{mm}$, were $5 \% \mathrm{~T}, 2.7 \% \mathrm{C}, 0.1 \%$ SDS, $0.075 \%$ ammonium peroxydisulfate, $0.05 \% \mathrm{~N}, \mathrm{~N}^{\prime} \mathrm{N}^{\prime}, \mathrm{N}^{\prime}$-Tetramethylethylenediamine (TEMED), and .05M phosphate pH 7.2. The samples, MDPF collagens, were prepared according to the first procedure; non-fluorescent samples were prepared for electrophoresis the same way except no $\mathrm{NaOH}, \mathrm{HCl}$ and MDPF solution were added. Either 2-mercaptoethanol 1-2\% ( $/ \mathrm{v})$ was added to reduce disulfide bonds or the disulfide bonds were broken by keeping the $\mathrm{pH}>10$ during heat denaturation. Coupling was performed before 2-mercaptoethanol reduction because mercaptoethanol interferes with the MDPF coupling. Samples were heat denatured at $56^{\circ} \mathrm{C}$ for 15 minutes before being applied to gels. The electrophoresis was performed at 6mAmps per tube for 4-6 hour at room temperature.

\section{Neville System}

The samples were electrophoresed as described by Neville (1971). This is a discontinuous Tris-borate buffer system with SDS only in the upper buffer and sample prepartion buffer. The upper buffer is 0.58 Tris, $0.25 \%$ boric acid and $0.1 \%$ SDS. The lower buffer is $0.15 \mathrm{M}$ TrisHCI $\mathrm{pH} 8.5$. The gels $(5 \mathrm{~mm} \times 55 \mathrm{~mm})$ used to separate collagen components were $6 \% \mathrm{~T}, 1 \% \mathrm{C}, 0.05 \%$ ammonium peroxydisulfate, $0.1 \%$ TEMED and $0.15 \mathrm{M}$ Tris HCl $\mathrm{pH}$ 8.5. The gels ( $5 \mathrm{~mm} \times 55 \mathrm{~mm}$ ) used to separate cyanogen bromide peptides were $15 \% \mathrm{~T}, 3 \% \mathrm{C}, 0.05 \%$ ammonium peroxydisulfate, 
$0.1 \%$ TEMED and $0.15 \mathrm{M}$ Tris HCl $\mathrm{pH}$ 6.1. The MDPF-collagen was prepared according to the second coupling procedure; the non-fluorescent collagen was prepared for electrophoresis the same way except no MDPF solution was added. AlI samples were heat denatured at $56^{\circ} \mathrm{C}$ for 15 minutes immediately before applying to gels. Before heat denaturation as above, cyanogen bromide peptide samples were boiled for $5^{\circ}$ minutes. The samples were electrophoresed into the stacking gels $(0.5-1.0 \mathrm{~h})$, at 0.2 mamps per tube; the current was increased to 1.5 mAmps per tube for electrophoresis in the running gel for 2.5-3.5 at room temperature.

E. Staining and Destaining

After electrophoresis, gels were removed from the gel tubes and stained for 4-16 hour with a Coomassie brilliant blue R-250 (Eastman) solution, $0.25 \%$ Coomassie blue $(w / v)$ in $7 \%$ acetic acid. Destaining was performed by first soaking the gels in $10 \%$ acetic acid, $30 \%$ methanol for 4-6 hour and then in 78 acetic acid. The acetic acid was changed twice dally until the gels were completely destained.

F. Scanning Procedure

1. Optical density (densiometric) scanning

After the gels were completely destained, they were placed in a gel boat of the Gilford Iinear transport. The absorbance of the coomassie blue stained bonds in the 
gels was measured using a Gilford spectrophotometer and the results recorded by a Corning 740 recorder. The sensitivity for recorder full scale deflection was set by a calibrated output absorbance of the Gilford. The slit plate was $.05 \times 2.36 \mathrm{~mm}$, the $\lambda=560 \mathrm{~nm}$.

2. Fluorescent gel (fluorometric) scanning After electrophoresis the gel tubes containing polyacrylamide gels were either sealed with parafilm and stored at $4^{\circ} \mathrm{C}$ or placed in a gel tube holder of the Gilford linear transport. Fluorescence scanning was performed with the previously described gel scanner equipment with the addition of the Gilford model 2515 fluorescent accessories. The model 2515 has a light source and a filter to provide an excitation energy at $390 \mathrm{~nm}$ at right angles to the optical path of the spectrophotometer. The filter placed between the gel tube and photometer allows emission light to pass through at $480 \mathrm{~nm}$. The model 2515 also includes a signal converter which performs an anti-log conversion of the photo meter signal. Therefore, light received is proportional to recorded signal. Quinine sulfate solutions in gel tubes sealed with parafilm were used to standardize measurements.

G. Photography

Coomassie blue stained gels were photographed using background lighting on Kodak Plus-X Pan film at a $f / I I$ for $1 / 125 \mathrm{sec}$. The camera was a $35 \mathrm{~mm}$ single lens reflex with bellows and a $75 \mathrm{~mm}$ enlarging lens. 
Fluorescent gels were placed in a black box, long wave bulb $366 \mathrm{~mm}$ (Eastern Corp.). The distance from gel to film plane was approximately $40 \mathrm{~cm}$. The exposure time for Kodak Plus X-Pan film was 4 minutes at a $f / 5.6$. U.V. Eilters were Kodak Wratten \#2B and \#2E sandwiched. Development was for $6-8$ minutes at $70^{\circ} \mathrm{F}$ in Kodak $\mathrm{D}-76$ diluted $1: 1$ with water.

H. Equations

1. Definitions for $8 T$ and $8 C$

$8 T$ is the percent acrylamide of the gel, defined as:

$$
T=\frac{a+B}{v}
$$

where $\underline{a}$ is the amount of acrylamide, $\underline{b}$ is the amount of bisacrylamide and $\underline{v}$ is the total volume of gel solution. $8 \mathrm{C}$ is the percent of cross-linking defined as:

$$
\text { \& } c=\frac{b}{a+b}
$$

2. Conversion from Absorbance to Relative Fluorescent Intensity

$$
R F I=\log ^{-1}(2-\mathrm{Abs})
$$

where RFI is the relative fluorescent intensity as measured by the percent of pen deflection. Abs is the absorbance units read from the Gilford spectrophotometer model 250. 
a. Quantitation of peak area. - The area under the curve for fluorometric scanning was recorded as:

RFI $\times \mathrm{mn}=\frac{\operatorname{area}\left(\mathrm{cm}^{2}\right) \times \mathrm{gel} \text { scan rate }(\mathrm{cm} / \mathrm{min}) \times 10(\mathrm{~mm} / \mathrm{cm})}{\text { scale factor }(\mathrm{cm} / \mathrm{RFI}) \times \text { chart speed }(\mathrm{cm} / \mathrm{min})}$

Area was measured with a Numonic Electronic planimeter model 210-117 with area given in $\mathrm{cm}^{2}$. The gel scan rate was usually $2 \mathrm{~cm} / \mathrm{min}$; the chart speed was usually $4 \mathrm{~cm} / \mathrm{min}$. The scale factors were $1,5,10,50,100$ where at scale factor I full scale would be $100 \mathrm{RFI}$ and at scale factor 50 full scale on the Corning recorder would be 2 RFI. The chart paper was $25 \mathrm{~cm}$ wide. The mm represent the relative band width on the gel.

\section{Statistics}

Linear regression lines for plots were drawn using a Hewlett Packard XY plotter model 9862A connected to a Hewlett Packard model 10 calculator.

$$
\text { a. Mean: } \bar{x}=\frac{\sum x_{i}}{n} \quad i=1,2, \ldots, n
$$

where $\mathrm{n}=$ sample size $-\mathrm{x}_{i}=$ value for each sample

b. Standard error: S.E. $=\sqrt{\frac{\sum\left(x_{i}-\bar{x}\right)^{2}}{n(n-1)}}$ 
c. Linear regression: $Y=\hat{b}_{0}+\hat{b}_{I} X+e$

$$
\begin{aligned}
& \text { slope: } b_{I}=\frac{\sum\left(X_{i}-\bar{X}\right)\left(Y_{i}-\bar{Y}\right)}{\sum\left(X_{i}-\bar{X}\right)^{2}} \\
& \text { intercept: } \hat{b}_{0}=\bar{Y}-\hat{b}_{I} \bar{X}
\end{aligned}
$$

Coefficient of determination $R^{2}=\frac{\left[\sum\left(X_{i}-\bar{X}\right)\left(Y_{i}-\bar{Y}\right)\right]^{2}}{\sum\left(X_{i}-\bar{X}\right)^{2} \sum\left(Y_{i}-\bar{Y}\right)^{2}}$

Standard error of estimate: $S E=\sqrt{\frac{\sum\left(Y_{i}-\hat{Y}_{i}\right)^{2}}{n=2}}$

d. Student $t$ test for slope

$$
T_{c}=\frac{\hat{b}_{1}-b_{1}}{s_{b_{1}}}-t_{n-2, I-\alpha / 2}
$$

e. Completely randomized design one way analysis of variance

$$
\text { ANOVA TABLE }
$$

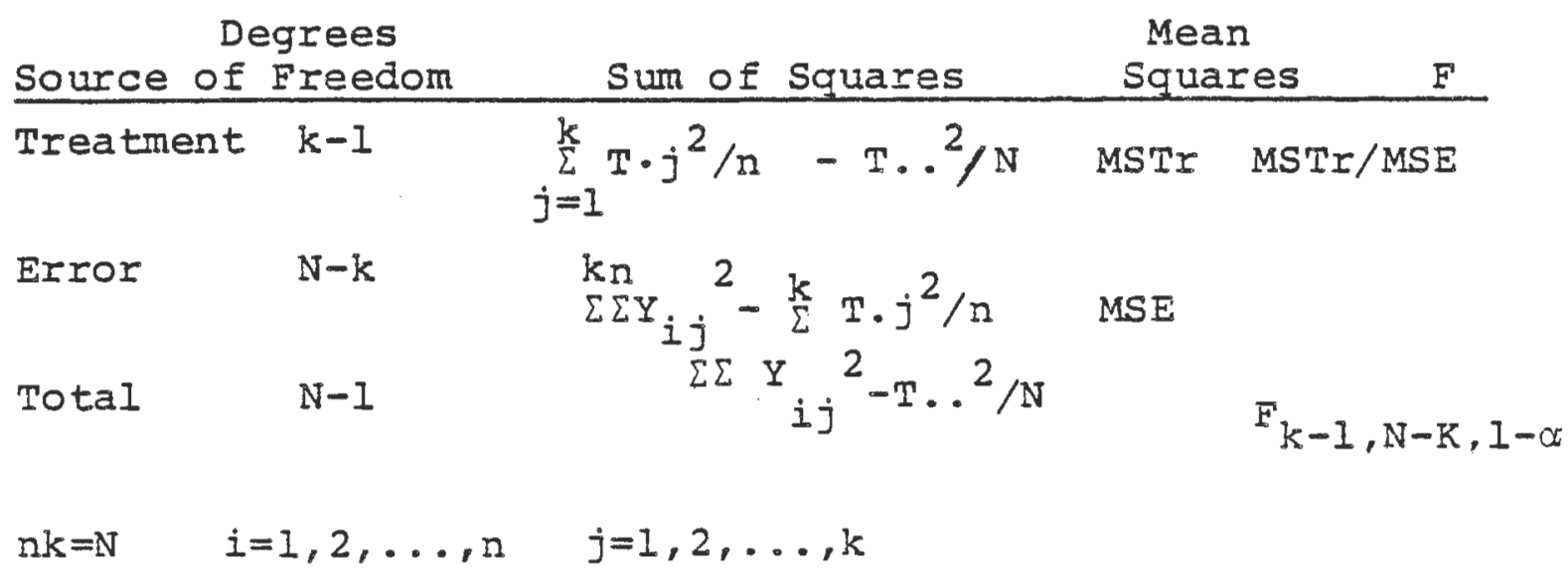


IV. RESULTS AND DISCUSSION

A. Characterization of MDPF-collagen in solution

In order to determine the temporal stability of MDPFcollagen, the fluorescence of a MDPF collagen solution was monitored for 30 minutes as shown in Figure 4 . Five minutes after coupling MDPF to collagen the fluorescent intensity reached a plateau level. Barger et al. (1977) stated that, MDPF was stable in gels for months. ThereFore, a further study was performed to determine the time for the fluorescent intensity to reach a plateau. Weigle et al. (1973) reported increases in the relative fluorescent intensity of MDPF-labeled proteins that reached plateaus after 60 minutes. Studies by Weigle et al. (1973) were performed with MDPF on Celite and this explains the slow fluorogenic reaction. Intermediates formed during MDPF coupling may be very strong fluors and this may explain the strong fluorescence observed in the first few seconds after the addition of MDPF. These proposed intermediates would not be detected by the procedure of Weigle, et al. (1973).

Both the buffer blank and the protein solution had the same relative fluorescence before coupling. After coupling, the relative fluorescence of the buffer blank was approximately $20 \%$ of that of the collagen solution 
used in this experiment. Urea and SDS both contribute to the fluorescence in the buffer blank. This was confirmed by measuring separately all the reagents in the sample preparative buffer. The fluorescence due to these constituents in the sample preparation buffer does not interfere with the protein fluorescence in gels following electrophoresis because they migrate ahead of the proteins.

In order to determine the optimum MDPF/protein ratio for maximum fluorescent intensity (Figure 5) various collagen and MDPF concentrations were coupled as described by the first procedure in Methods. When $2 \mathrm{mg} / \mathrm{ml} \mathrm{MDPF}$ was used in the coupling reaction, the increase in fluorescence is linearly related to collagen concentration up to $\mathrm{I} \mathrm{mg} / \mathrm{mI}$ collagen. With $2 \mathrm{mg} / \mathrm{ml}$, the MDPF concentration must be increased to $4 \mathrm{mg} / \mathrm{ml}$. At high MDPF concentrations (10 $\mathrm{mg} / \mathrm{ml}$ ) with high protein concentrations ( $2 \mathrm{mg} / \mathrm{ml}$ ) there was a decrease in fluorescence. The decrease in fluorescence from high collagen and MDPF concentrations may be due to an absorption and/or a quenching effect. Ragland et al. (1974) demonstrated that with fluorometric gel scans of myoglobin (made fluorescent with fluorescamine) I $\mathrm{mg} / \mathrm{ml}$ fluorescamine had less fluorescent intensity than $0.5 \mathrm{mg} / \mathrm{ml}$ fluorescamine.

The increase in the plateau level of relative fluorescence linearly correlated with the increase in collagen concentration (Figure 5). The minimum MDPF concentration for maximum relative fluorescence is twice the collagen 


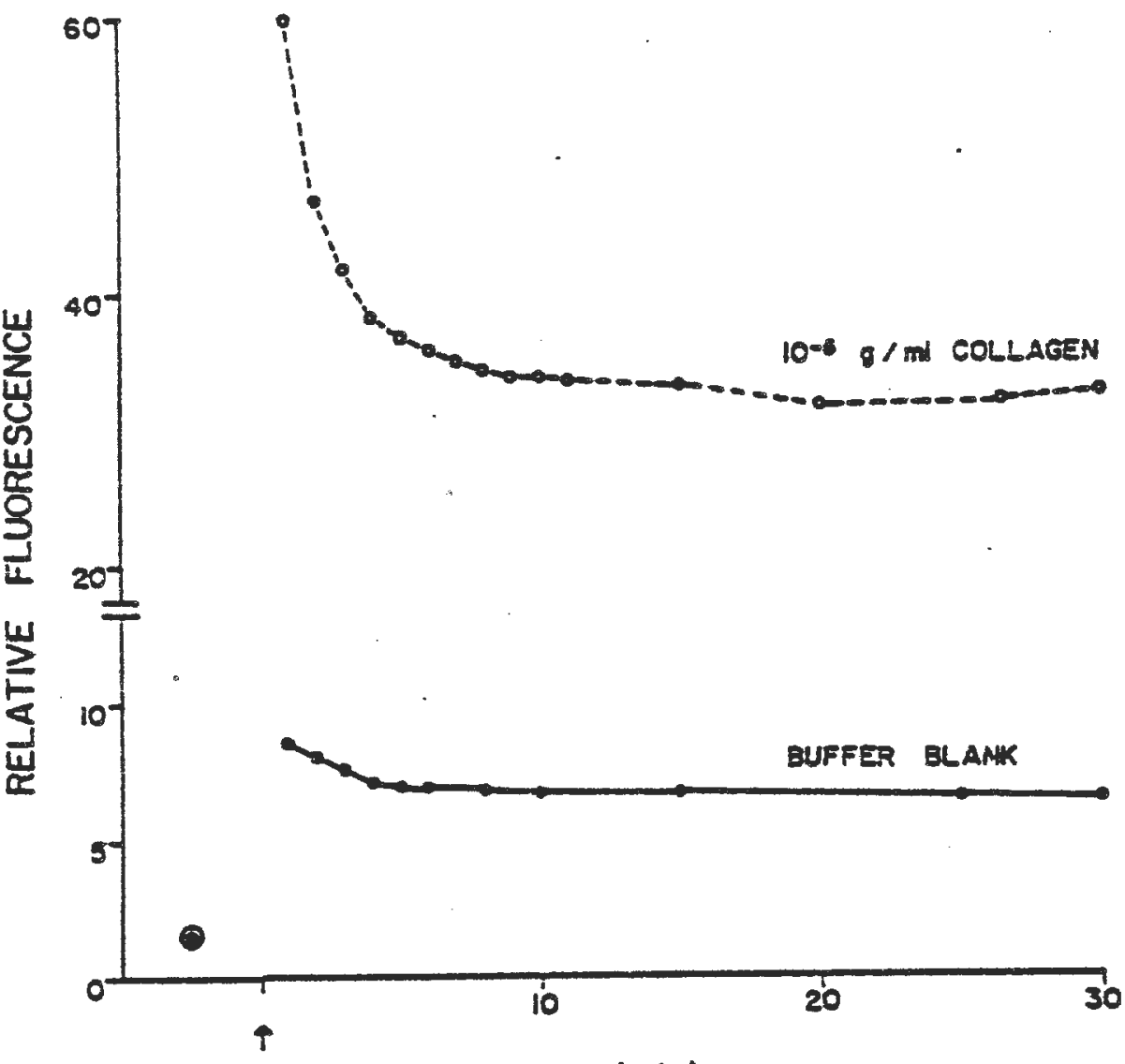

TIME (min)

Fig. 4. Rate of fluorogenetic reaction of MDPF with collagen. Samples were coupled in a $1 \mathrm{~cm} \times 1$ cm cuvete according to the first coupling procedure except instead of returning the $\mathrm{pH}$ to neutrality, the samples were placed in a fluorometer and their relative fluorescence were measured. $(\psi)$ is when the MDPF solution was added to the samples. ( $Q$ ) is the relative fluorescence of the buffer and $10^{-5} \mathrm{~g} / \mathrm{mI}$ collagen before coupling. $(0)$ is $10^{-5} \mathrm{~g} / \mathrm{ml}$ collagen after coupling and ( ) is buffer blank after coupling. 


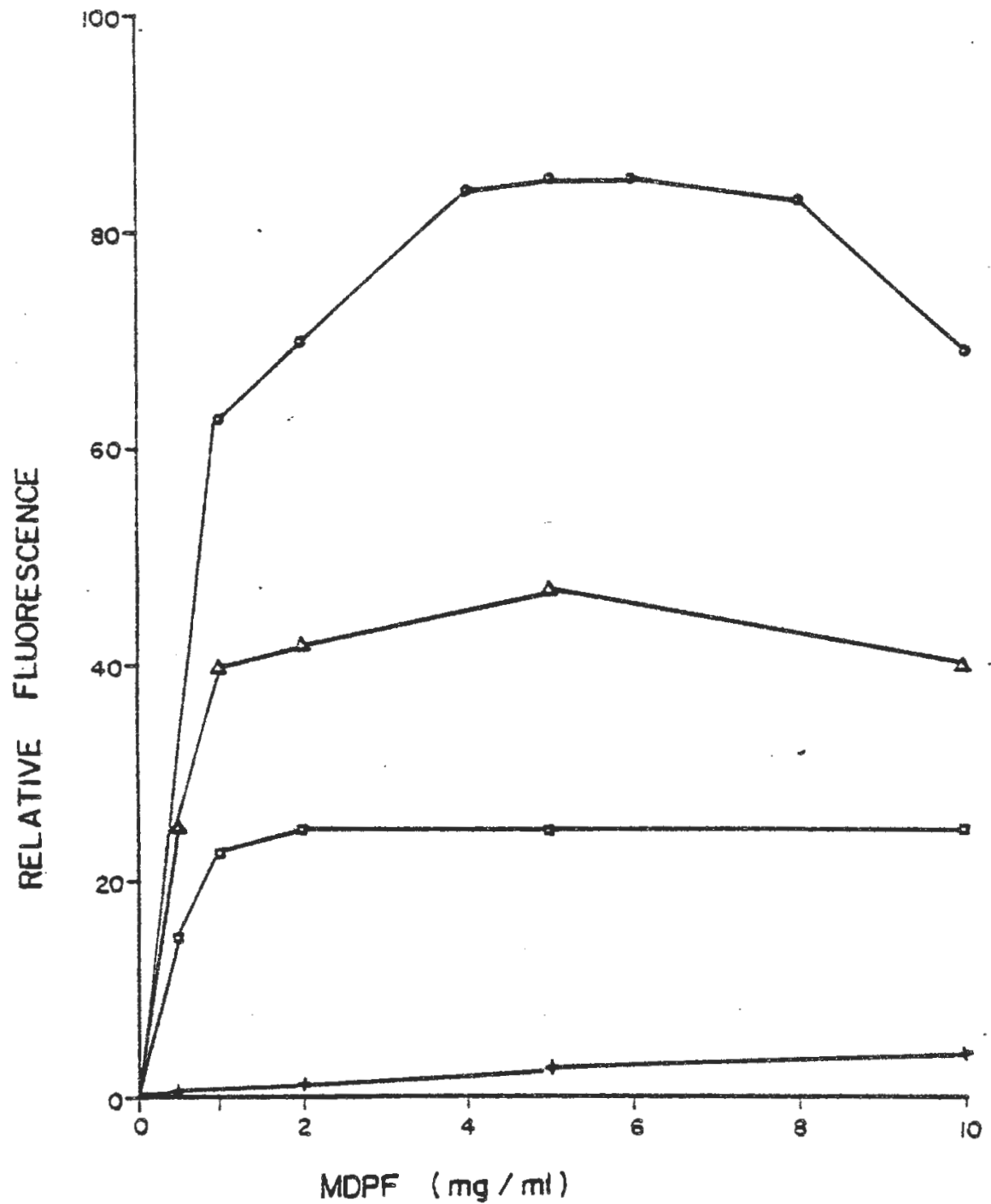

Fig. 5. Relative fluorescence of collagen/MDPF ratio. Samples were coupled according to the first procedure and then diluted 1:30 with distilled water: $2 \mathrm{mg} / \mathrm{ml}$ collagen (0), $1 \mathrm{mg} / \mathrm{ml}$ collagen $(\Delta), 0.5 \mathrm{mg} / \mathrm{ml}$ collagen $(\boldsymbol{D})$, and buffer blank (t). 
concentration. This represents a four times excess of fluor to ligand site on the collagen on a molar basis.

B, Electrophoretic migration - effect of MDPF

The initial quantitation of MDPF-collagen on SDSPAGE was performed according to the procedure of Furthmayr and Timpl (1971). Later work was performed by Neville (1971) procedure. The Neville system is preferred because it provides separation of $M D P F-\alpha 1$ and $M D P F-\alpha 2$ chains and the time required for elecgrophoresis is shorter. However, after several days stored at $4^{\circ} \mathrm{C}$ the $M D P F-\alpha 1$ and $M D P F-\alpha 2$ diffuse into a single band. In the Furthmayr and Timpl (1971) procedure the gel bands diffuse very little when stored at $4^{\circ} \mathrm{C}$. This may be due to the precipitation of the SDS in the cold. Figures 6 and 7 are photographic records and scans of gels Iun according to the procedure of Furthmayr and Timpl (1971). The al chain separated from the $\alpha 2$ chain when stained in Coomassie blue but not when labelled with MDPF.

The separation of collagen o chains (i.e., $\alpha I$ from a2) on SDS-polyacrylamide gels is an anomaly. According to theory proteins separate only by molecular weight on SDS-PAGE, because after binding to SDS all the proteins have a net negative charge (Weber and Osborn, 1969). The percent acrylamide $(\% \mathrm{~T})$ and percent crosslinking $(\mathrm{g} C)$ determine the mobility of protein towards the anode (Figure 8). The collagen œchains have identical molecular 

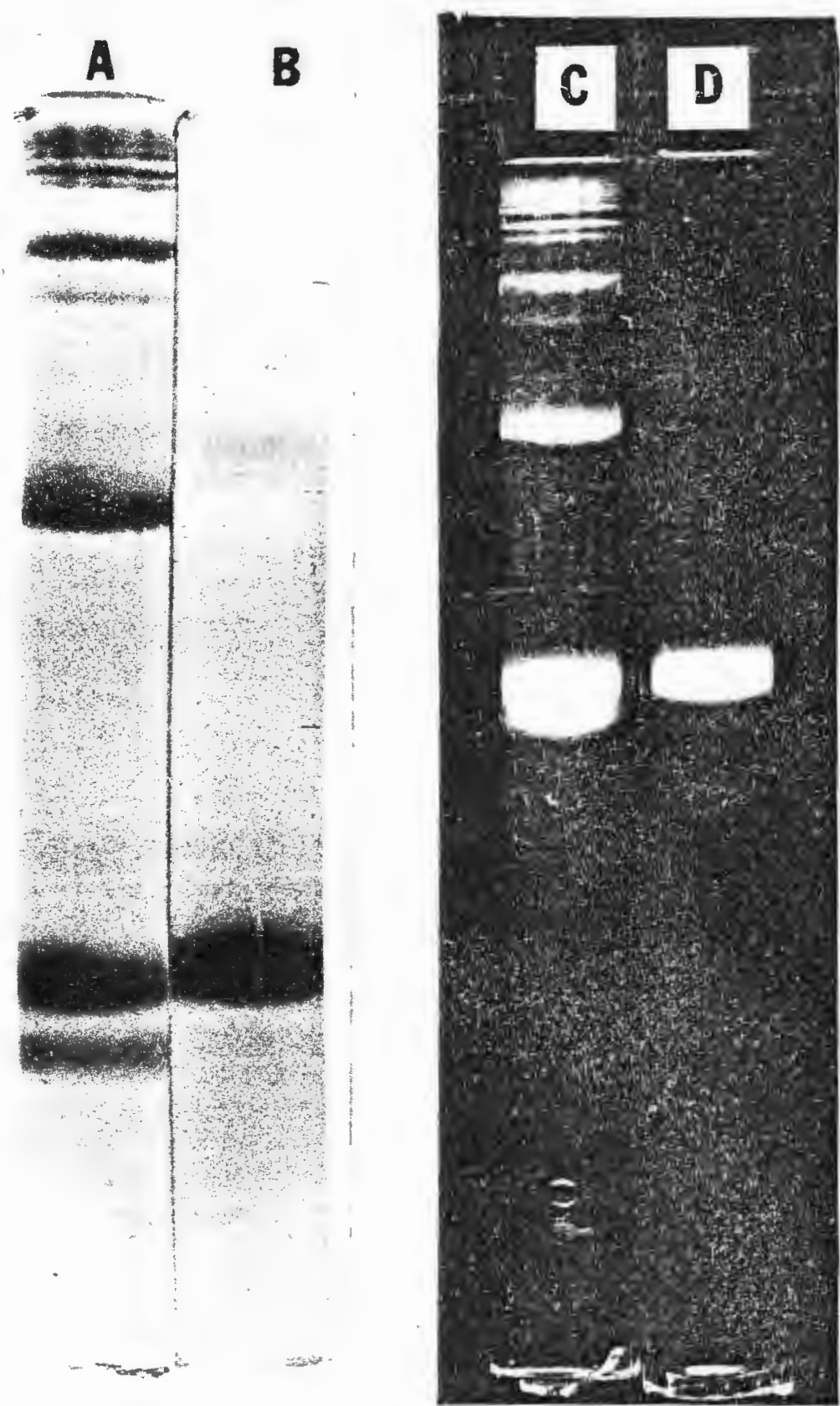

Fig. 6. Photographic record of gels of Type I collagen (A) and purified $\alpha 1$ (I) (B) stained with Coomassie blue after electrophoresis; Type I collagen (C) and $\alpha I$ (I) (D) labelled with MDPF before electrophoresis. 

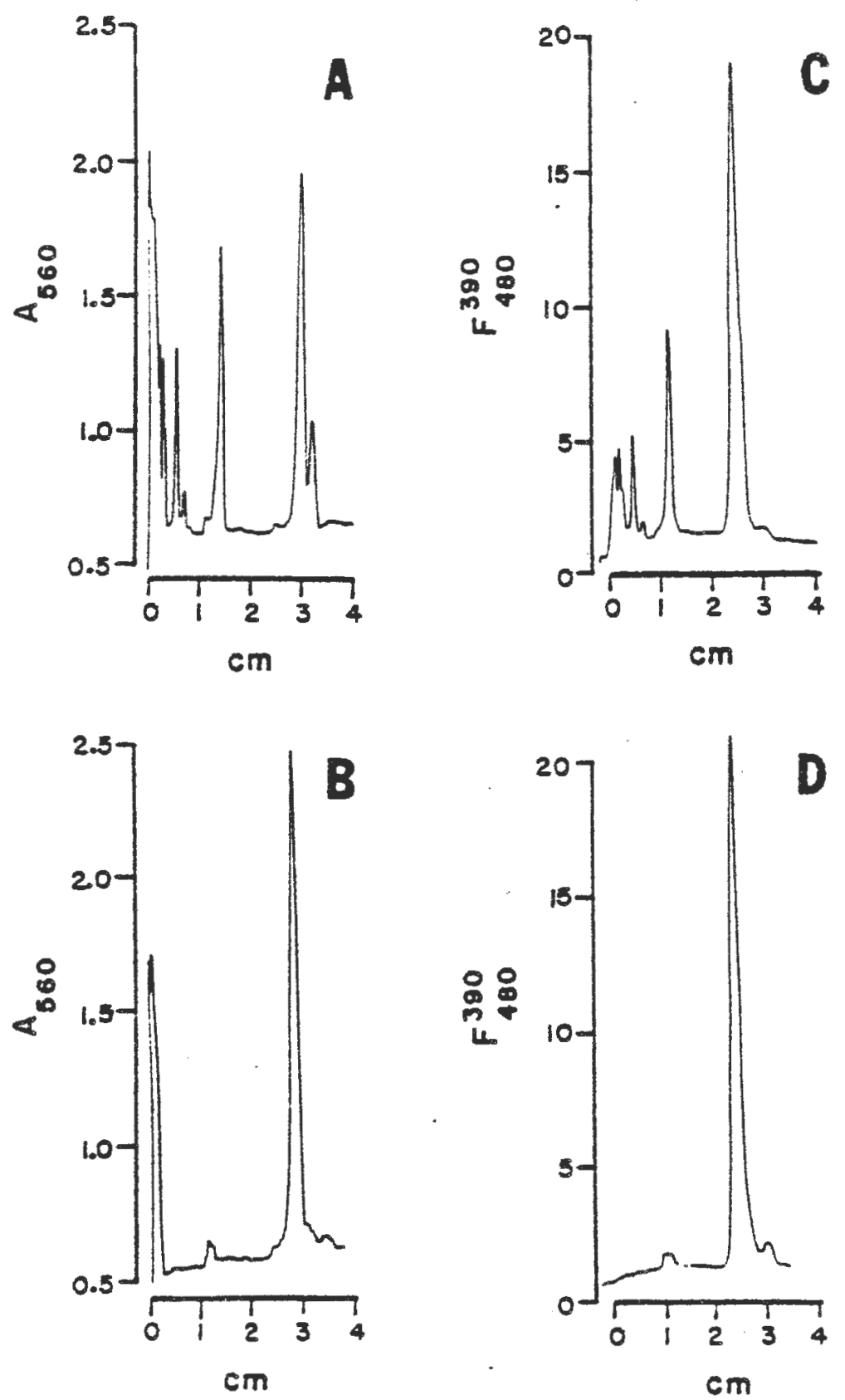

Fig. 7. Densiometric scans of $20 \mathrm{\mu g}$ Type I coliagen (A), $10 \mathrm{hg}$ purified al (I) (B): fluorometric scans of $20 \mathrm{\mu g}$ MDPF-Type I collagen (C) and $10 \mu \mathrm{g} \mathrm{MDPF- \alpha I(I)} \mathrm{(D).}$ scans taken from gels in Fig. 6 . 


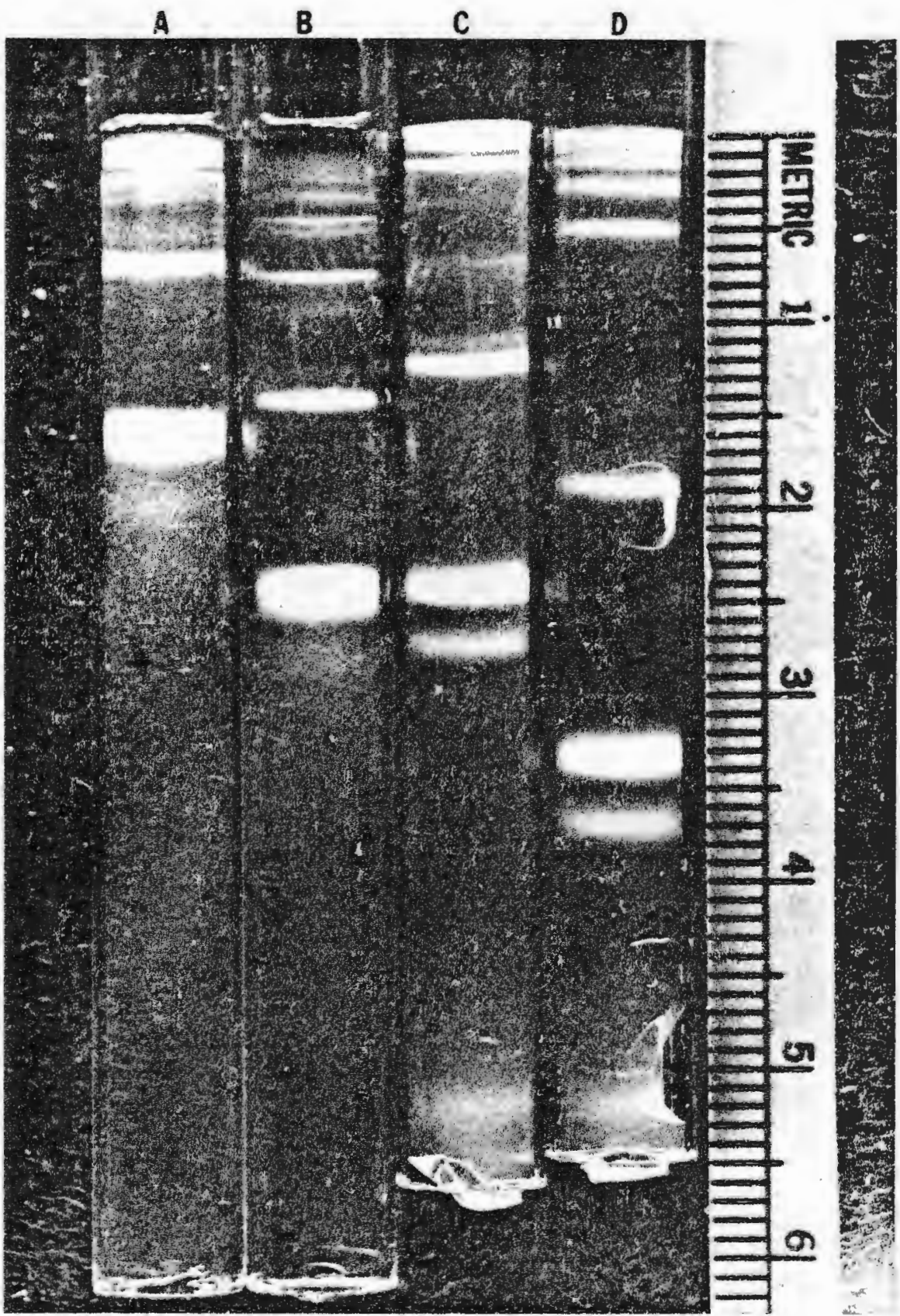

Fig. 8. Comparison of Furthmayr and Timpl procedure to Neville procedure for separation of MDPF-Type I collagen. Furthmayr and Timpl procedure $5 \% \mathrm{~T}$ and $2.7 \% \mathrm{C}$ (A), 5\% $\mathrm{T}$ and $18 \mathrm{C}$ (B); Neville procedure $7 \% \mathrm{~T}$ and $1 \% \mathrm{C}(\mathrm{C}), 6 \% \mathrm{~T}$ and I\% C (D). Electrophoresis time was approximately four hours for all four gels. 
weights $\pm 5 \%$ as determined by amino analysis (Miller, $1976 a$ and Fujii; Kuhn, 1975; and Epstein, 1974). Svojtkova et al. (1973) demonstrated by parallel Ferguson flots (both with and without SDS) that $\propto I(I)$ and $\propto 2$ separation is due to a difference in net charges on the protein. No one has reported isoelectrophocusing of $\alpha$ chains. MDPF' is coupled to collagen via the primary amines ( $\varepsilon$-amines of lysine and hydroxylsine) and masks the positive charge. (MDPF is non-polar but fluorescamine has a carboxyl group.) As shown in Table I and Figure 9, MDPF causes an increase in mobility of o chains with the change in $\alpha I$ (III) $>\alpha I$ (I) $\gg \alpha_{2}$. The relative increase in mobility is opposite to the respective $R_{f}$ values before MDPF. One would expect the $R_{f}$ to decrease on SDS-PAGE due to the $10 \%$ increase in molecular weight of the MDPFchains over uncoupled o chains.

Both MDPF- $\alpha 1$ (I) and a 2 increase in mobility with $\alpha I(I)$ increasing more than $\alpha 2$. This explains why the separation of $\alpha I$ (I) and $\alpha: 2$ is decreased after coupling with MDPF and also why MDPF- $\alpha I$ (I) and $\alpha 2$ did not separate on the Furthmayr and Timpl (1971) gels procedure. This suggests that lysines ( $\varepsilon$-amines) contribute to the charge difference responsible for the separation of al(III) from $\alpha$ (I) from $\alpha 2$ but other factors are also contributing. The effect of MDPF on a chains migration contributes to our understanding of the anomaly of a chain separation 


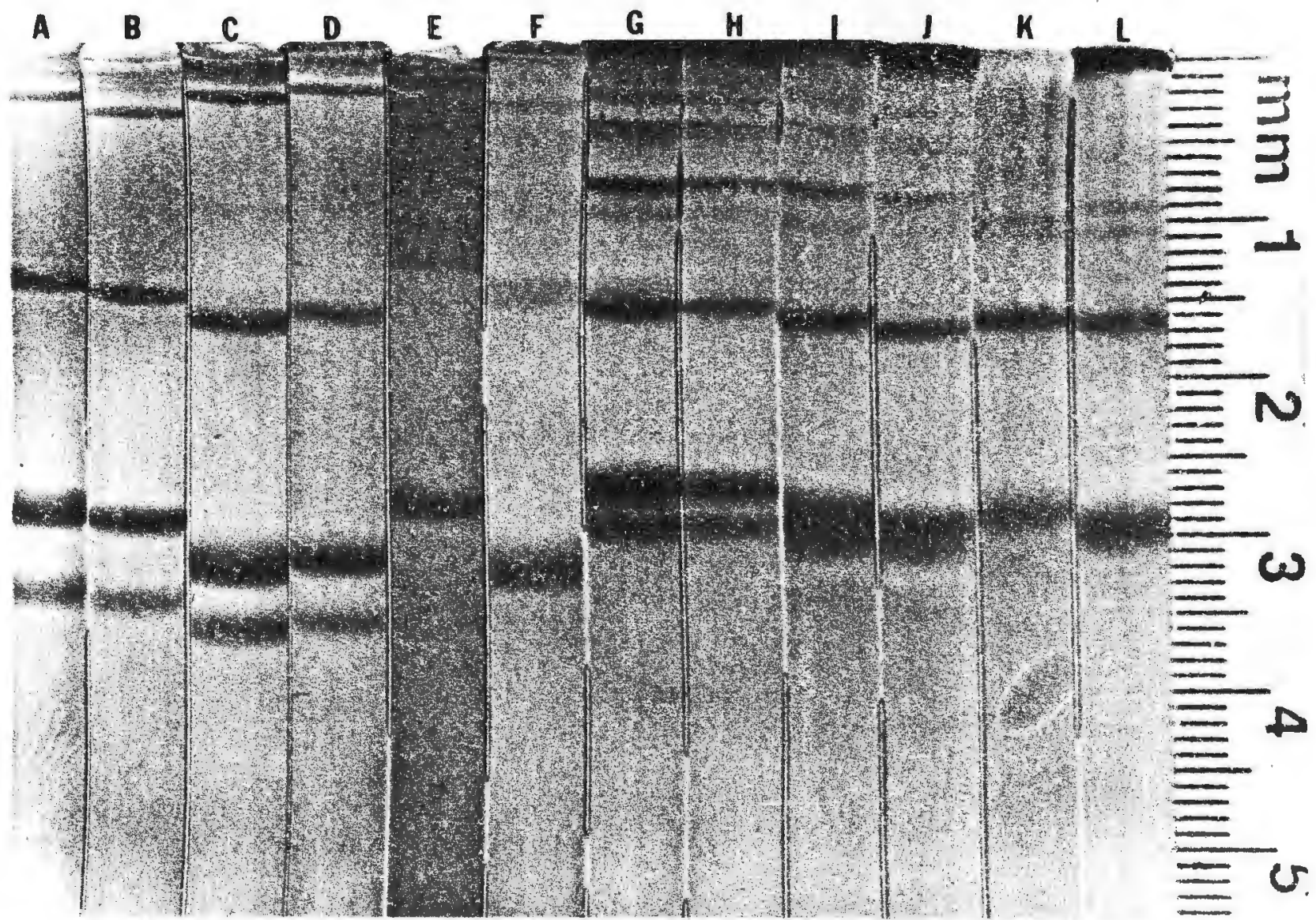

Fig. 9. Effect of MDPF on the migration of collagen components in SDS-PAGE. Gels were stained with Coomassie blue immediately after electrophoresis. Gels A-F were electrophoresed by the Neville procedure; gels G-L by the Furthmayr and Timpl procedure. The samples electrophosed are: $20 \mu \mathrm{g}$ Type I (A), $10 \mu \mathrm{g}$ Type I (B), $20 \mu \mathrm{g}$ MDPFType I (C), $10 \mu \mathrm{g}$. MDPF-Type I (D), 10. $\mathrm{g}$ Type III (E), $10 \mu \mathrm{g} \mathrm{MDPF-}$ Type III (F), $20 \mu \mathrm{g}$ Type I (G), $10 \mu \mathrm{g}$ Type I (H), $20 \mu \mathrm{g}$ MDPF-Type I (I) $10 \mu \mathrm{g}$ MDPF-Type I (J), $10 \mu \mathrm{g}$ Type III (K), $10 \mu \mathrm{g}$ MDPF-Type III (I). Gels B and C from Fig. 8 are I and C from this figure before staining and destaining. 
Table I

EFFECT OF MDPF ON THE MIGRATION OF COLLAGEN COMPONENTS IN

COLLAGEN
COMPONENTS

× 2

$\alpha I(I)$

$\alpha I(I I I)$

$$
\text { SDS-PAGE }
$$

$$
R_{\text {I VALUES }}
$$

\begin{tabular}{ccc}
\hline$\frac{M D P F}{+M D P F}$ & $\frac{\Delta}{.712(.002)}$ \\
$.705(.004)$ & $.710+.007$ \\
$.614(.002)$ & $.648(.002)$ & +.034 \\
$.606(.012)$ & $.666(.004)$ & +.060 \\
$.356(.002)$ & $.370(.006)$ & +.014 \\
$.321(.004)$ & $.345(.006)$ & +.024
\end{tabular}

$\beta 12$

$\beta 11$

The polyacrylamide gels were run according to the Neville
(1971) procedure $(T=5.5 \%, C=1 \%)$. After electrophoresis, the gels were stained with Coomassie blue and destained in $7 \%$ HAc. $R_{f}$ values are the mean of two gels (range). 
but raises additional questions. For example, since lysine content is similar for all the of chains (Miller, 1976a) why is there a preferential increase in mobility?

\section{Quantitation of of Chains}

In order to quantitata different collagens, $\alpha$ chains from Type I and III were purified by CMC and agarose gel chromatography. The single fluorometric band obtained from each purified $\alpha$ chain was used later to establish linearity and assay limits. The scanned area recorded for each fluorometric peak was measured by planimetry three times with the average area under the curve having a $\pm 3 \% \mathrm{SE}$. The same values for the areas were obtained from gels whether the gels were scanned immediately after electrophoresis or stored at $4^{\circ} \mathrm{C}$ in gel tubes and then scanned. These scans show, however, that the peaks were sharper immediately after electrophoresis than those stored for several days. A scan of 10,000 $\mathrm{ng} M D P F-\alpha I$ (I) is shown in Figure 7D. The area is expressed as RFI $X \mathrm{~mm}$ which takes into account the relative sensitivity (set by the fluorescent control unit) and the ratio of gel scan rate to chart speed. Therefore, the area term is the product of relative fluorescent intensity and relative band width. Each point shown in the standard curve of Figure 10 represents a different gel of MDPF-al(I). The data were obtained from 3 non-replicate electrophoresis runs. The regression $\mathrm{R}^{2}$ was .998 . 


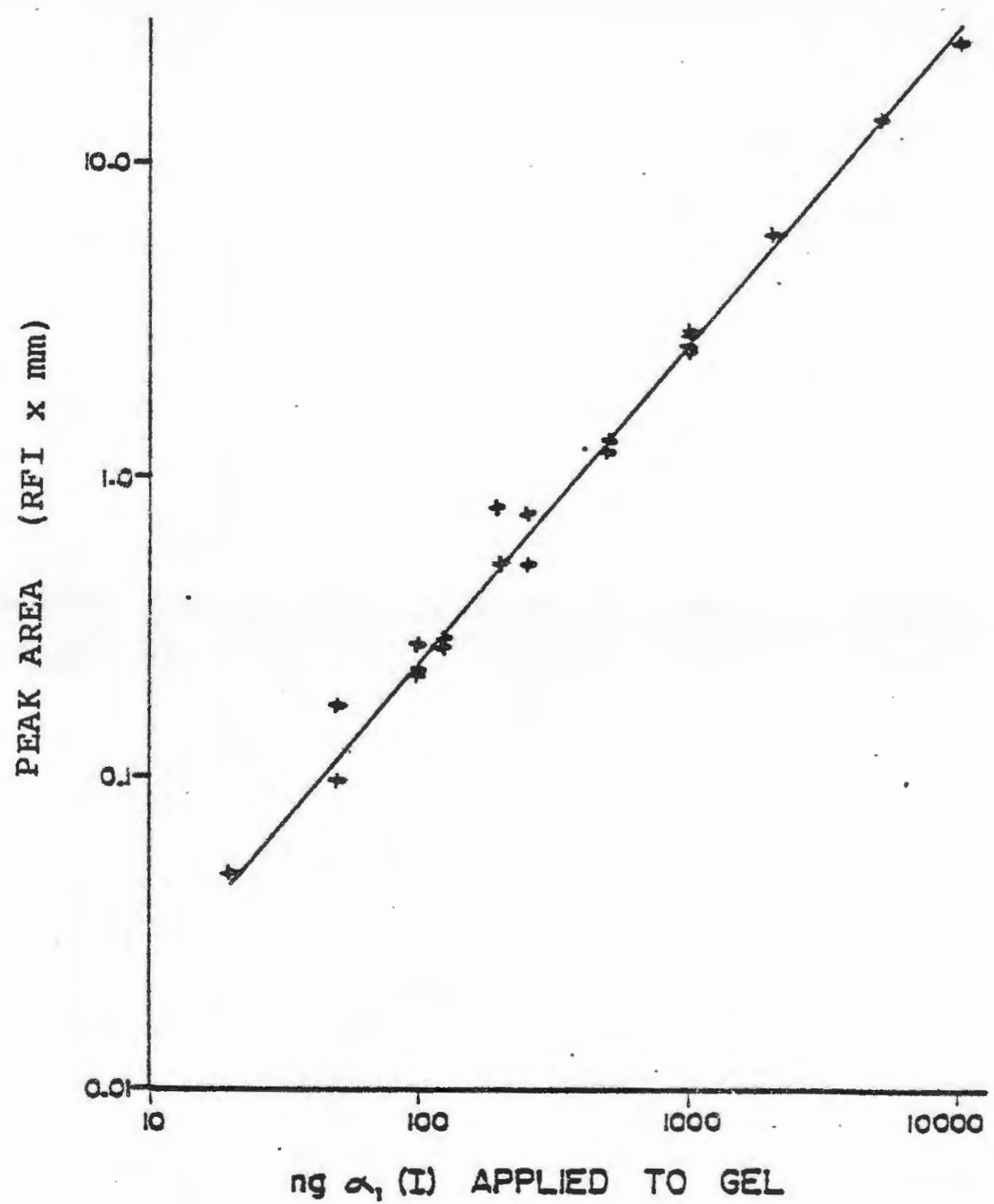

Fig. 10. Standard curve for MDPF-aI (I) versus peak area. Each point represents a different gel. The data is a composite of three nonreplicate determinations. The area is expressed as RFI $x \mathrm{~mm}$ as defined in Methods. The Iine was determined by Iinear regression. 
Figure 11 shows the standard curve from three different $\alpha$ chain; $\alpha$ (I), $\alpha I$ (III) and $\alpha 2$. Each data point is the average of three non-replicate electrophoresis runs with $a \pm 6 \% \mathrm{SE}$. The solid lines represent the linear regression of each a chain. The dotted line represents the relative fluorescent intensity for quinine sulfate at $10^{-6}$ and $10^{-7} \mathrm{~g} / \mathrm{ml}$, used for recorder calibration. Similar standard curves were obtained for all three a chains.

Raglad et al. (1974) demonstrated with fluorometric scanning that three different proteins yielded standard curves with different slopes dependent on primary amine content (i.e., lysine). However, in our study of collagen a chains little difference was found between the standard curves generated by the three different collagen chains, due to similarity in structure and amine content. $\alpha I(I), \alpha 2$ and $\alpha I$ (III) chains were used rather than Type I and Type III collagens because these contain (dimers) and higher molecular weight forms. This is important since the collagen crosslinks are derived from lysines and hydroxylsines and some ligand sites would be unavailable for MDPF coupling. Estimating the amount of higher molecular weight forms of collagen using chains as standards, could result in an underestimate. This most likely would be an insignificant difference because only 3-12\% of the lysine hydroxylsines are thought to participate in crosslinking, dependent upon tissue, animal age and pathology (Tanzer, 1976; Scott, P.G., et al. 1976). This error is less than the error incurred 


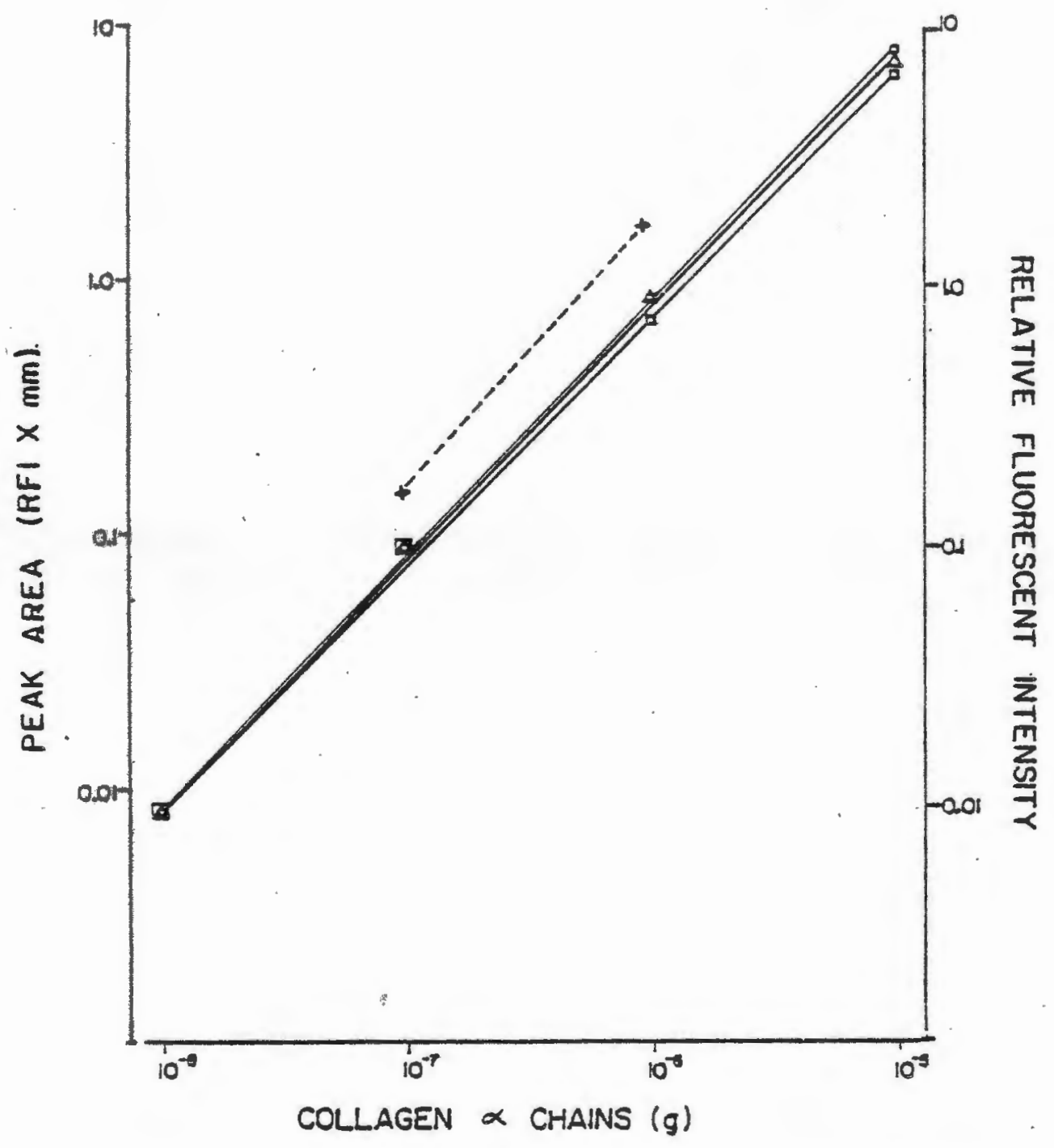

Fig. 1I. Standard curve for RFI $x$ mm versus MDPFcollagen $\alpha$ chains. The area beneath the curve (e.g. Fig. 5D) was quantitated as stated in Methods. The line for each collagen $\alpha$ chain species was determined by linear regression: $\alpha I$ (I) (O), $a I$ (III) $(\Delta)$, and $\alpha_{2}(\square) . \quad \mathrm{x} \cdots \mathrm{x}$ are the relative fluorescent intensity values for quinine sulfate in $0.1 \mathrm{~N} \mathrm{H}_{2} \mathrm{SO}_{4}$ $\left(10^{-7} \& 10^{-6} \mathrm{~g} / \mathrm{ml}\right)$ which were used to calibrate the recorder. 
by the estimation of collagen hydroxyproline because there is $35 \%$ more 4-hydroxyproline in Type III collagen than Type I (Click and Bornstein, 1970; Chung and Miller, 1974). Also Clq may contribute some non-collagen 4-hydroxyproline. In the estimation of collagen types by radioactive proline a correction factor is not considered for the $15 \%$ difference in imino content of $\alpha 1$ (I) and $\alpha_{2}$ (Click and Bornstein, 1970).

Since there is approximately the same primary amine content in the collagen chains $( \pm 58),(F u j i i$ and Kuhn, 1975), the standard curves are similar and there is therefore no correction factor necessary for quantitating these three different genetic types of $\alpha$ chains against a single standard. The quantitation af collagen by MDPFSDS-PAGE has the following advantages over staining with Coomassie blue: 1) it is more rapid, the fluorescent bands can be observed during electrophoresis with a long wave U.V. lamp and quantitated immediately after electrophoresis; 2) there is less variability $\pm 6 \%$ SE vs 10-15\%; there is a wider range of linearity, $10 \mathrm{ng}$ to $10 \mu \mathrm{g}$ and improved sensitivity, $10^{-8} \mathrm{~g}$. 


\section{Type III collagen quantitation}

Type III collagen is covalently bound as a trimer and higher molecular weight form by disulfide bonds. The decrease in $\gamma$ (trimer) and highermolecular weight form following reduction by mercaptoethanol should be accounted for by increase in $\alpha$ (monomer) and $\beta$ (dimers) forms. Figure 12 shows desiometric and fluorescent scans of $10 \mathrm{ug}$ of type III collagen; the decrease in $\gamma$ and higher molecule weights can be accounted for by the increase in $\alpha$ and $\beta$ as measured by fluorometric scans but not densiometric scans (Table II).

It is important to be sure that the disulfide bonds have not been broken in the extraction procedure or preparation for electrophoresis, because $\alpha I$ (III) does not separate from $\alpha I(I)$ and it could give a false result during heat denuration (preparation of sample for electrophoresis). Also, disulfide bonds will break if the pH is not returned to neutrality after MDPF coupling. Conformation of the validity of this system can be demonstrated with the cyanogen bromide peptide mapping because some $\alpha I$ (III) $-C B$ peptide separate from $\alpha I(I)-C B$ peptides. 

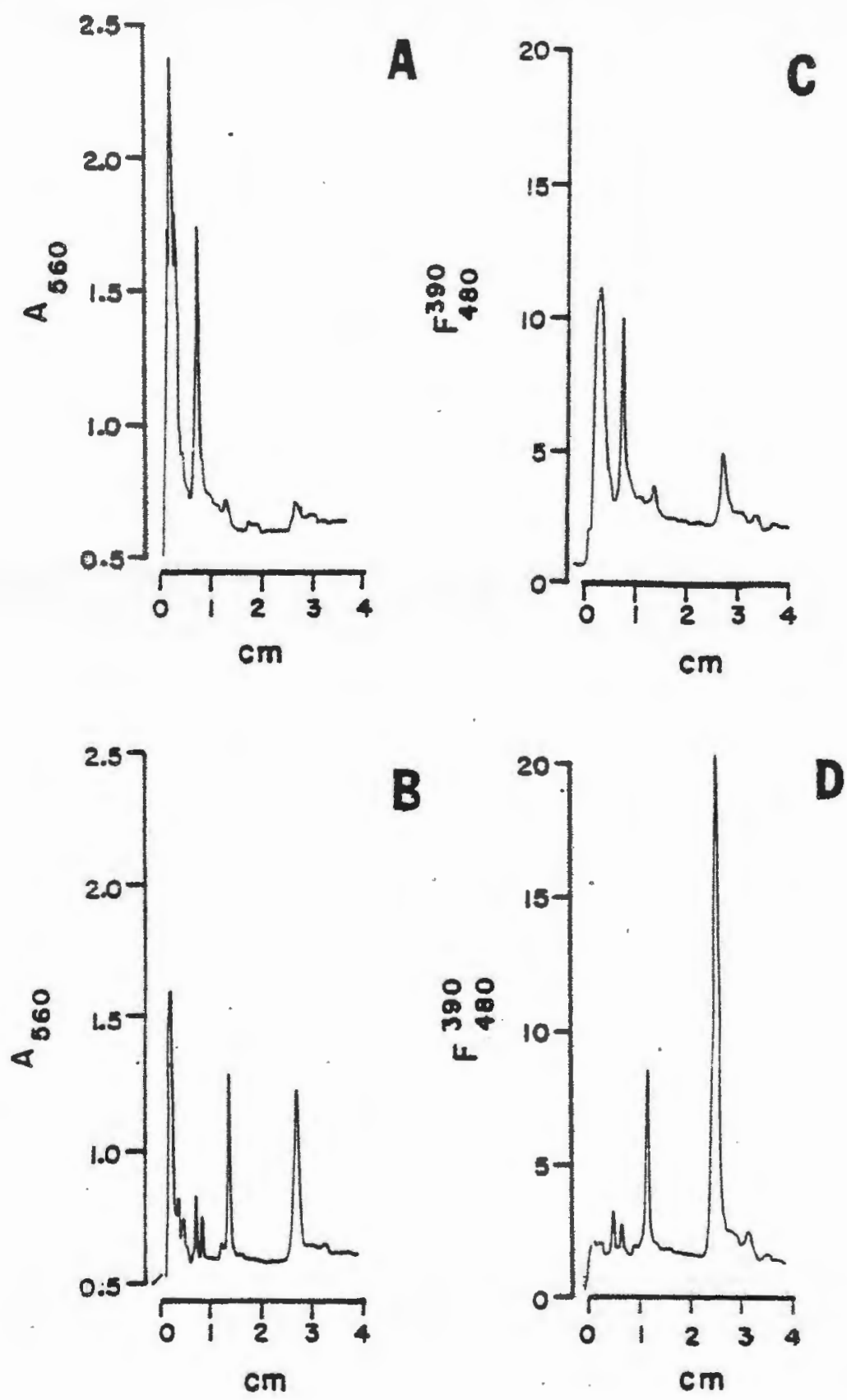

Fig. 12. Gel scans of Type III collagen before reduction ( $A$ and $C$ ) and after reduction with mercaptoethanol ( $B$ and $D$ ) by densiometric scans ( $A$ and $B$ ) and fluormetric scans (C and D). 
A Comparison of the Peak Areas for Type III Collagen Obtained by Fluorescent Scanning (MDPF-SDS-PAGE) and Densiometric Scanning (Coomasste Blue) of Acrylamide Gels Before and After Reduction

\begin{tabular}{|c|c|c|c|c|}
\hline & \multicolumn{4}{|c|}{ Peak Area $\left(\mathrm{cm}^{2}\right)$} \\
\hline & \multicolumn{2}{|c|}{$\begin{array}{c}\text { Fluorescence } \\
\text { F } 390 \\
480\end{array}$} & \multicolumn{2}{|c|}{$\begin{array}{l}\text { Absorbance } \\
\qquad A_{560}\end{array}$} \\
\hline & $\begin{aligned} & \text { higher } \\
& y+\quad \text { M.W. } \\
&\end{aligned}$ & $\alpha+\beta^{1}$ & $\begin{array}{r}\text { higher } \\
\gamma+\quad \text { M.W. } \\
\end{array}$ & $\alpha+\beta$ \\
\hline Before Reduction ${ }^{2}$ & $9.00 \pm 21^{3}$ & $1.52 \pm .05$ & $13.89 \pm 65$ & $1.01 \pm .08$ \\
\hline After Reduction & $1.00 \pm .01$ & $8.73 \pm .17$ & $5.27 \pm .09$ & $4.72 \pm .26$ \\
\hline $\begin{array}{l}\text { Change due to } \\
\text { reduction }\end{array}$ & -8.00 & +7.21 & -8.62 & +3.71 \\
\hline $\begin{array}{l}\text { Percent recovered after } \\
\text { reduction } 4\end{array}$ & $90 \%$ & & & $3 \%$ \\
\hline
\end{tabular}

$1 \alpha=$ monomers, $\beta=$ dimers, $\gamma=$ trimers, higher M.W. = higher molecular weights.

2 Reduced samples were incubated with 1-2\% 2-mercaptoethanol for $15 \mathrm{~min}$ before electrophoresis. 3 mean \pm S.E. for 3 determinations.

4

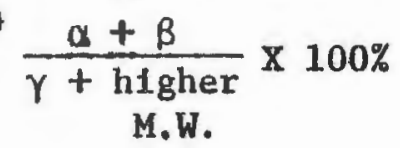


E. Effect of distance migration on peak area

One of the major problems with quantitating proteins in SDS-PAGE by densiometric scanning after Coomassie blue staining is thatprotein peak area is dependent upon distance migrating resulting in change in both linear range and sensitivity. Thus, a correction factor is necessary for distance migrated (Fishbein, 1971). An analysis of variance shows there was no significant difference between distance migrated and fluorescent peak area of MDPF- 1 (I) (TableIII). There was a decrease in peak height and a broadening with increased migration (Figure 13). This is one explanation why with type III collagen reduction, peak area remains the same when determined by fluorometric scanning but not by densiometric scanning. 


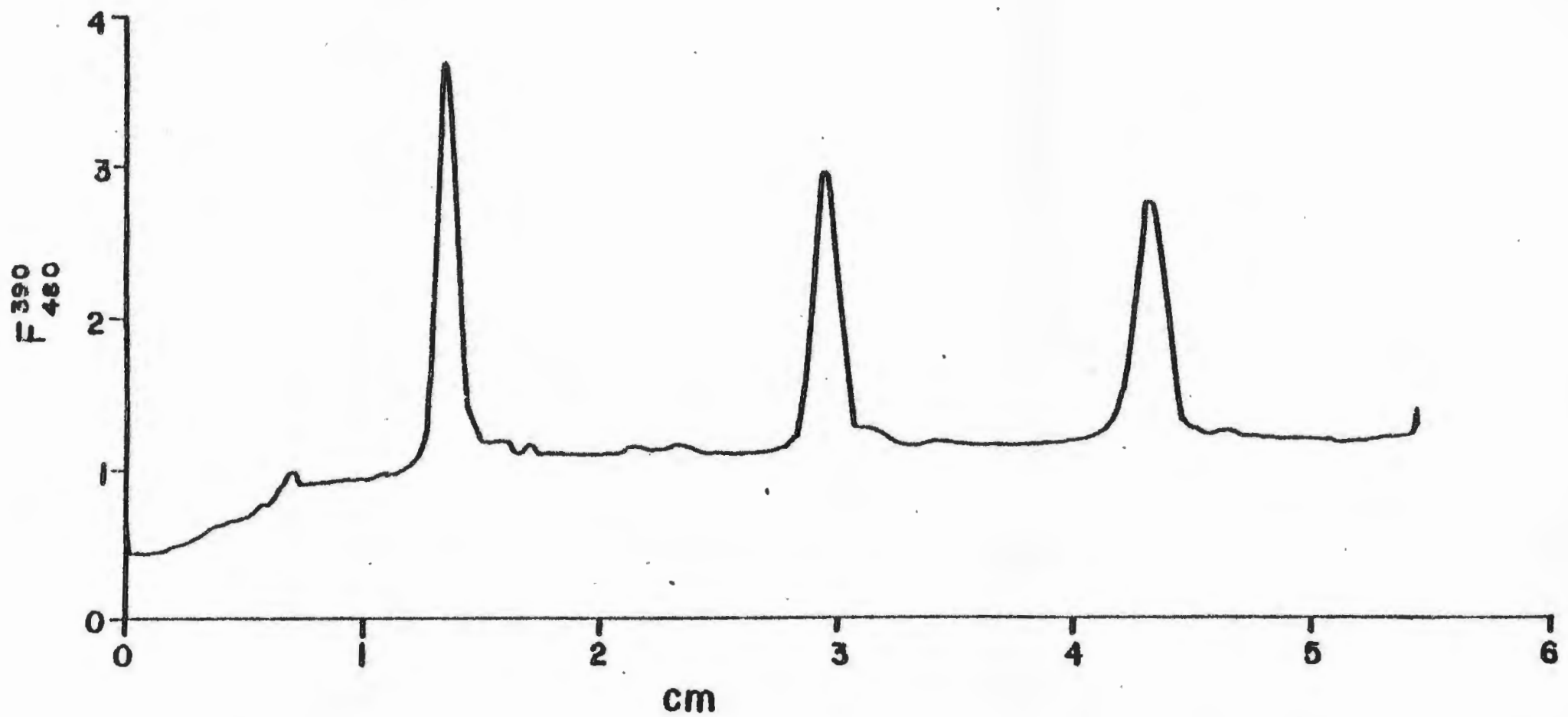

Fig. 13. Effect of distance migrated on fluorescent peaks. A sample of 1 H.g MDPF-al(I) was applied to the gel every two hours. The total electrophoresis time was six hours. The scan rate of the gel was $1 \mathrm{~cm} / \mathrm{min}$ and the chart speed was $4 \mathrm{~cm} / \mathrm{min}$. 
TABLE III

EFFECT OF DISTANCE MIGRATED ON PEAK AREA

OF MDPF-OI (I) COLLAGEN

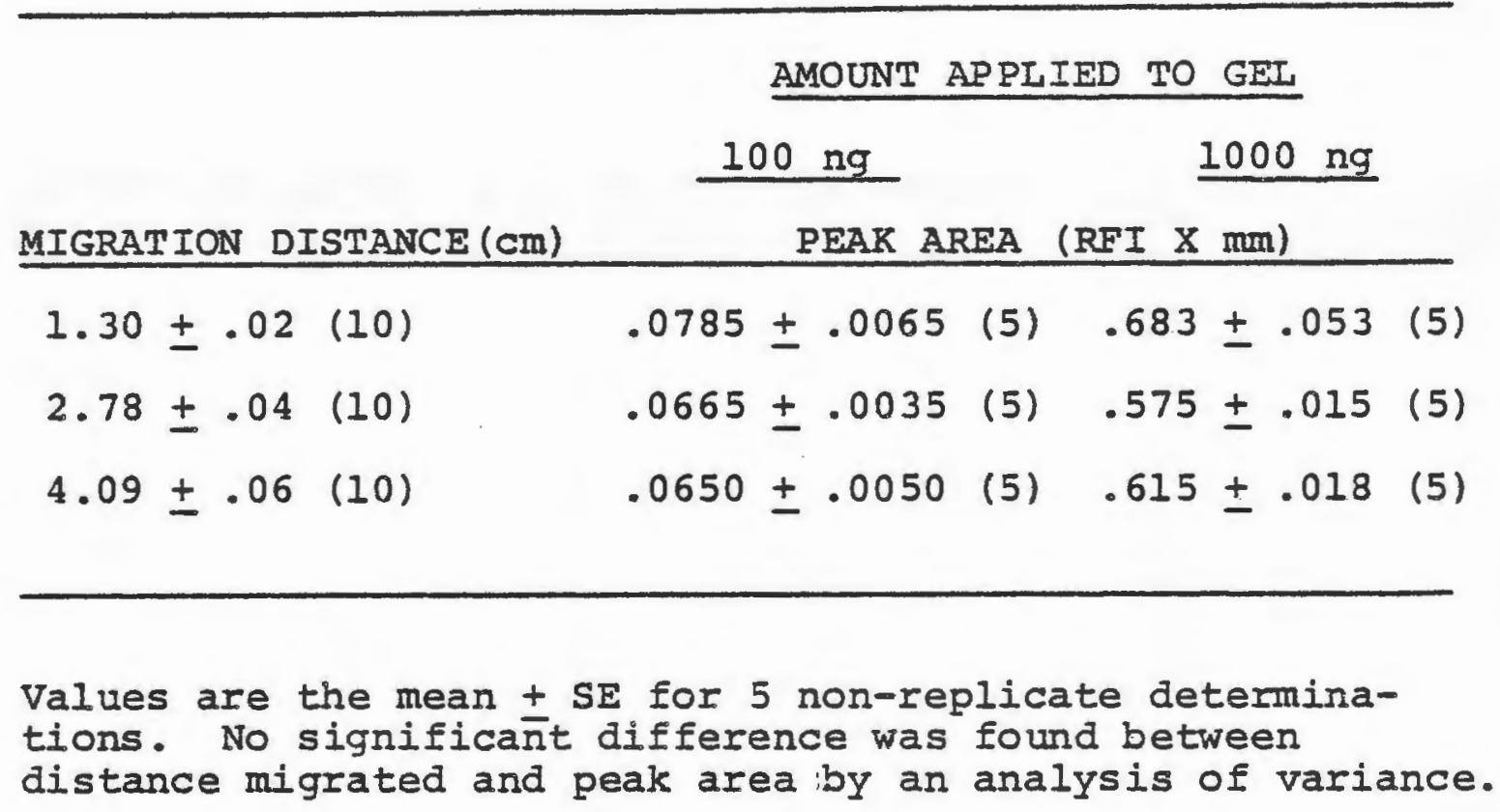


F. Cyanogen bromide peptides from Type I and III collagen The identification of the cyanogen bromide cleavage products of collagen (CP peptide) is based on their relative mobility in SDS-PAGE. Table IV: is a list of CB peptides from $\alpha I$ (I), $\alpha$ l(III) and $\alpha, 2$ according to their molecular weight. The cyanogen bromide peptides separate by molecular weight on SDS-PAGE with the lower molecular weight peptides having the greater relative mobility. Figure 14 shows the fluorometric scans obtained from $C A B$ digested $\alpha_{I}(I), \alpha_{I}$ (III), and $\alpha_{2}$. Based upon the measured relative mobility $\left(R_{f}\right)$ from Figure 14 and the possible molecular weight forms of the cyanogen bromide peptides (Table III) a semi-log plot of molecular weight vs $R_{f}$ can be derived (Figure 15). The coefficient of determination $\left(R^{2}\right)$ for this regression analysis for all three $\alpha$ chain cyanogen bromide peptides is 0.989 .

The cyanogen bromide peptide profiles found here were similar to Scott and Weiss (1976) and Benya et al. (1977). Both the $R_{f}$ values differ due to different gel systems used in these labs.

It should be possible to quantitate the amounts of type I and type III collagen present in a mixture of collagen, since there are some $C B$ peptides from type III collagen that have molecular weights that differ from Type I collagen (Figure 16). An attempt to quantitate the percent type III in a mixture of I and III is shown 
Table IV

CYANOGEN BROMIDE CLEAVAGB PRODUCTS OY COLLAGEN a CHAINS

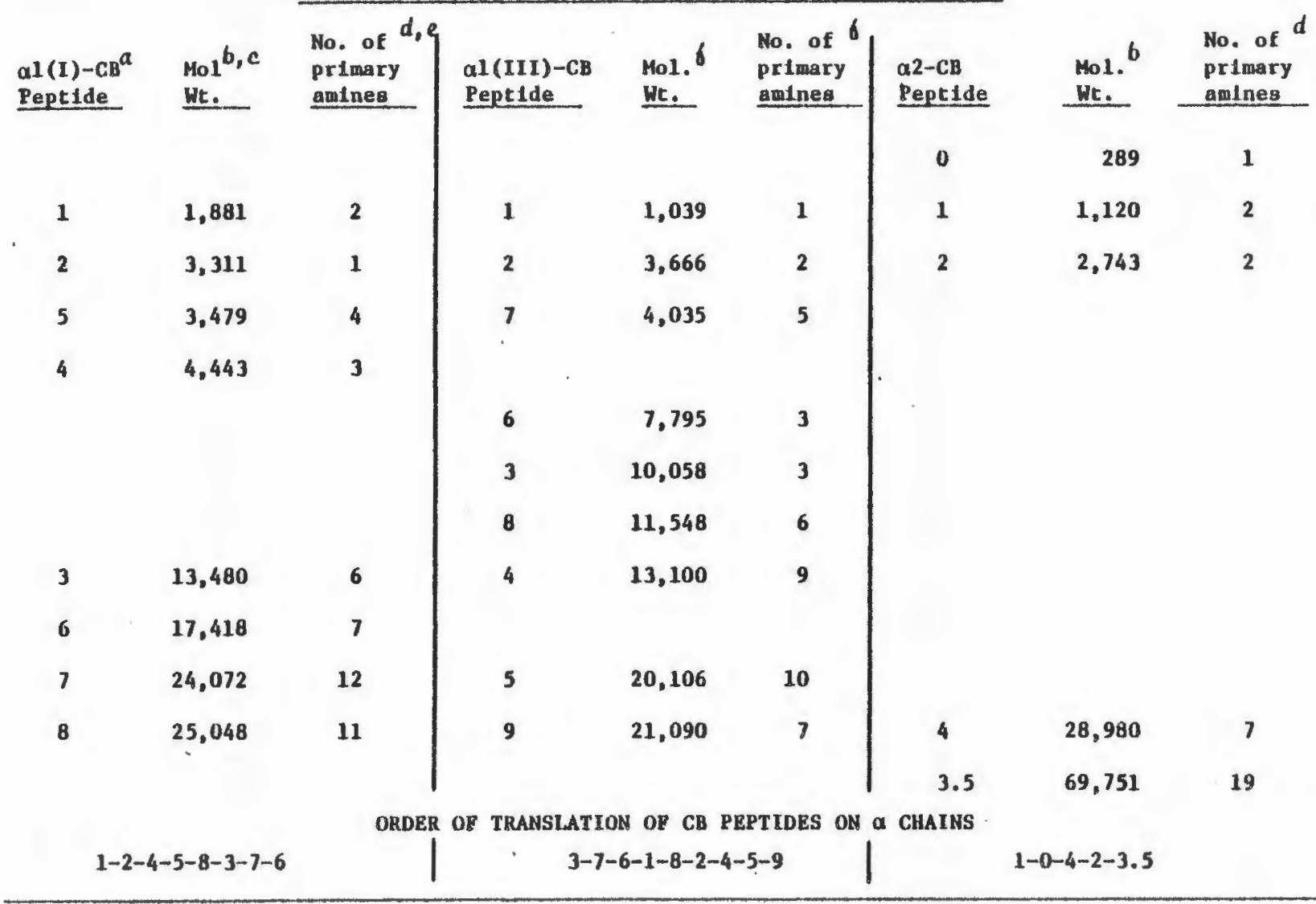

a Identification number of $\mathrm{CB}$ peptides represents the order of elution of $f$ of a colc colum.

Scott and Wefss (1976): Connec. Tisaue Res. 4, 107.

c Mol. wt. baśed on amino acid composition.

d Kühn (1972): Eur. J. Bfochem. 30: 163.

Total of LYS + HLY + N TERMINAL.

6 Chung, Keele and M11ler (1974): Btochem. 13: 3459. 


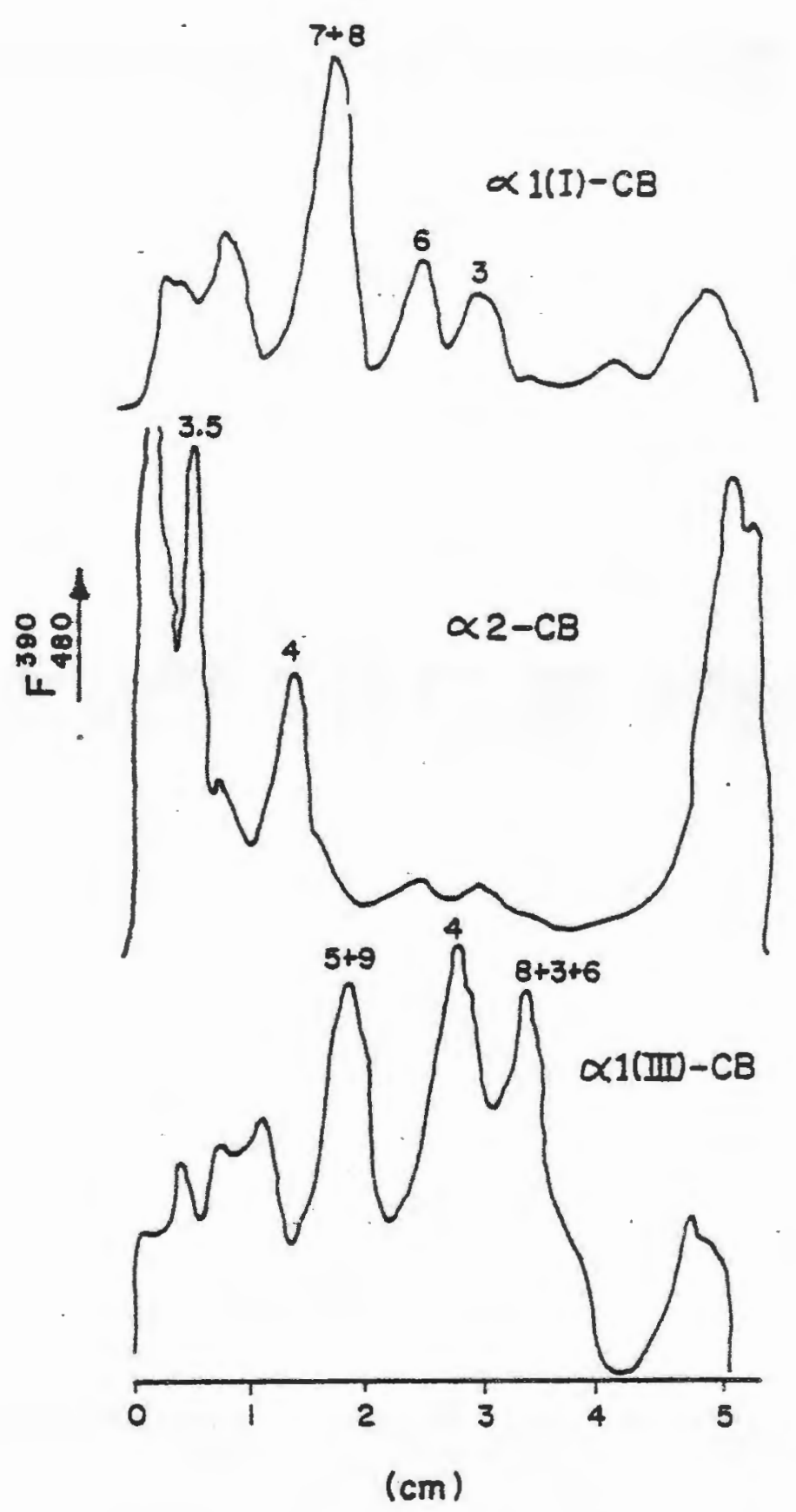

Fig. 14. Fluorometric gel scans of purified $\not$ chains CB peptides. Three purified $\alpha$ chains of collagen were cleaved with CNBr. The peptides were coupled with MDPF and then electrophoresed according to Neville (1971) procedure. Identification of CB number is based on their relative mobility. 


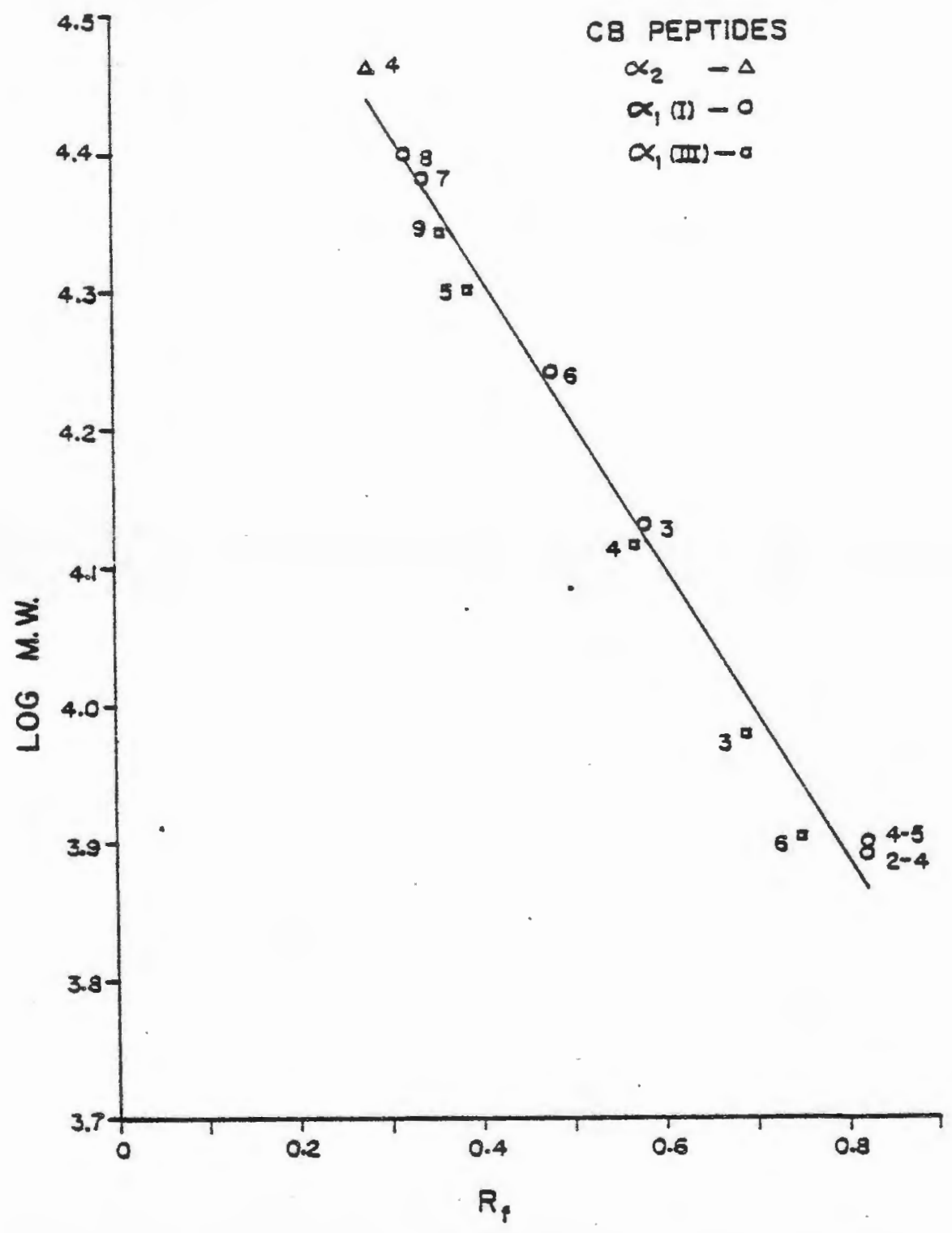

Fig. 15. A plot of the relative mobilities versus the logarithm of the molecular weight of cyanogen bromide peptides from $\alpha$ (I) (O), $\alpha$ I (III) (D, and $\alpha 2(\Delta)$. The numbers are the $C B$ peptide number as explained in Table III. The relative mobilities were calculated from Fig. 14. 


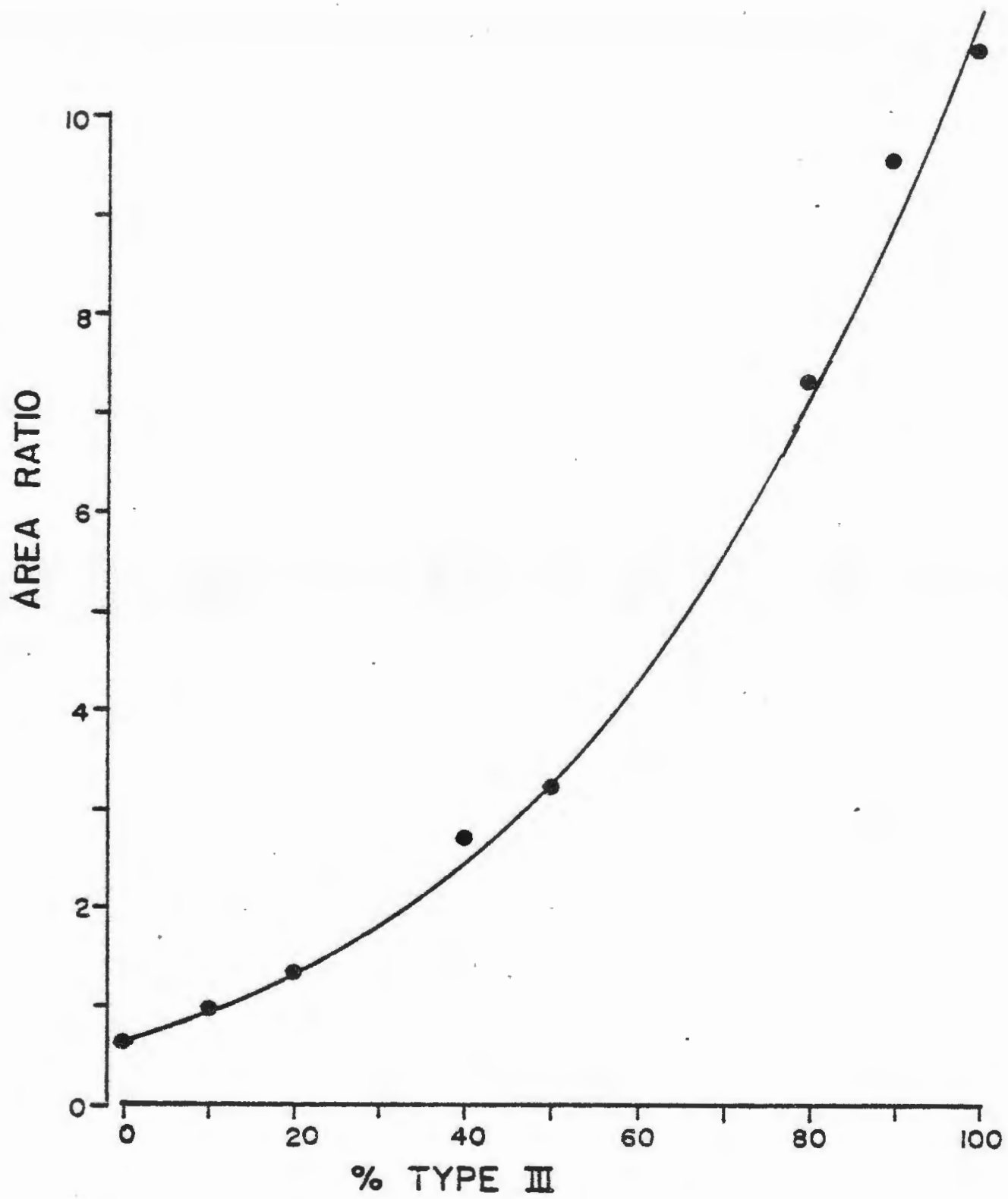

Fig. 16. A standard curve for $\frac{}{8}$ Type III by CB peptide fluorescent areas. Type I and Type III collagen were cleaved with cyanogen bromide. The 100\% Type III is $10 \mu \mathrm{g}$ of III-CB peptides, 08 Type III is $10 \mathrm{\mu g}$ Type ICB peptides and $50 \%$ Type III is $5 \mu \mathrm{g}$ III-CB peptides and $5 \mathrm{\mu g}$ I-CB peptides. The samples were made fluorescent by coupling with MDPF before electrophoresis. The fluorescent area used for Type III was from IIICB $4,8,3,6$. The fluorescent area for Type I was from I-CB6. The area ratio was obtained by dividing the RFI $x$ mm for III-CB4, 3,3,6 by the REI x mm for I-CB6 and III-CB $4,8,3,6$. 
in Figure 17. The standard curve is not linear. Crystal et al. (1977) found a similar result with the quantitation of radioactive cyanogen bromide peptides from type I and III collagen. The reason for this non-linear standard curve is that the amount of radioactivity or RFI $\mathrm{x} m$ for the $C B$ peptides is not equal for type I and III collagen as was shown with the achain quantitation.

An alternative method is to quantitate the cyanogen bromide peptides for type I and III collagen and plot the amount of I and III for the specific cyanogen bromide peptides. Using this method one can obtain a plot in which each $\alpha$ chain is quantitated (Figure 18).

The advantage of quantitating collagen types by cyanogen bromide peptides is that both the amount of type I and III collagen can be quantitated from a single gel by measuring the area beneath the curves for the peaks associated with type I and type III collagen cyanogen bromide cleavage products. The disadvantage of this method compared to quantitation by achains is that it is ten times less sensitive. The cyanogen bromide digestion of each sample would require the time-consuming process of lyophilization to remove the CNBr and to concentrate the sample for SDS-PAGE. The cyanogen bromide peptides profiles are very complex and also there is not always complete cleavage at each methionine residue such that some peptides are contiguous cyanogen bromide peptides. This is because the methiodine residues 


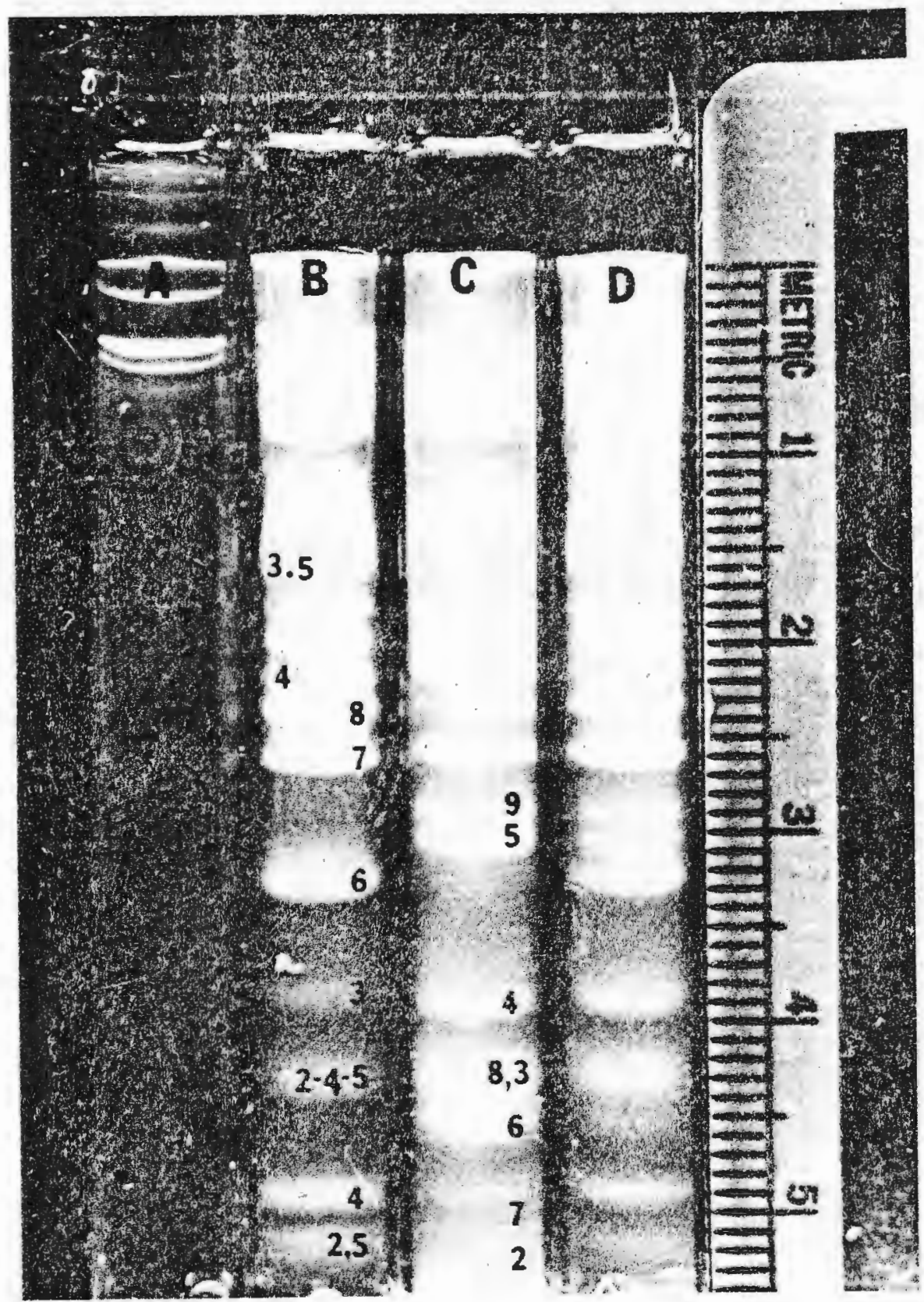

Fig. 17. Photograhic record of MDPE-collagen CB peptides. $10 \mathrm{\mu g}$ of MDPF-Type I collagen (A) before cyanogen bromide digestion (the $\alpha 1$ and $\alpha 2$ separate with the Neville system even at 15음 and 3C). $20 \mu \mathrm{g}$ Type I collagen after CNBr digestion (B); numbers on the left are from $\alpha \cdot 2$, the numbers on the right are $C B$ peptides from $\alpha I(I)$. The CB pep tides obtained from $20 \mu \mathrm{g}$ Type III (C), the numbers are $\propto I$ (III) -CB numbers. $10 \mu G$ I-CB and $10 \mu \mathrm{g}$ III-CB are in (D). The higher molecular weight peptides are either uncleaved products or crosslinked peptides. The coupling of MDPF to the CB peptides was just prior to electrophoresis. 


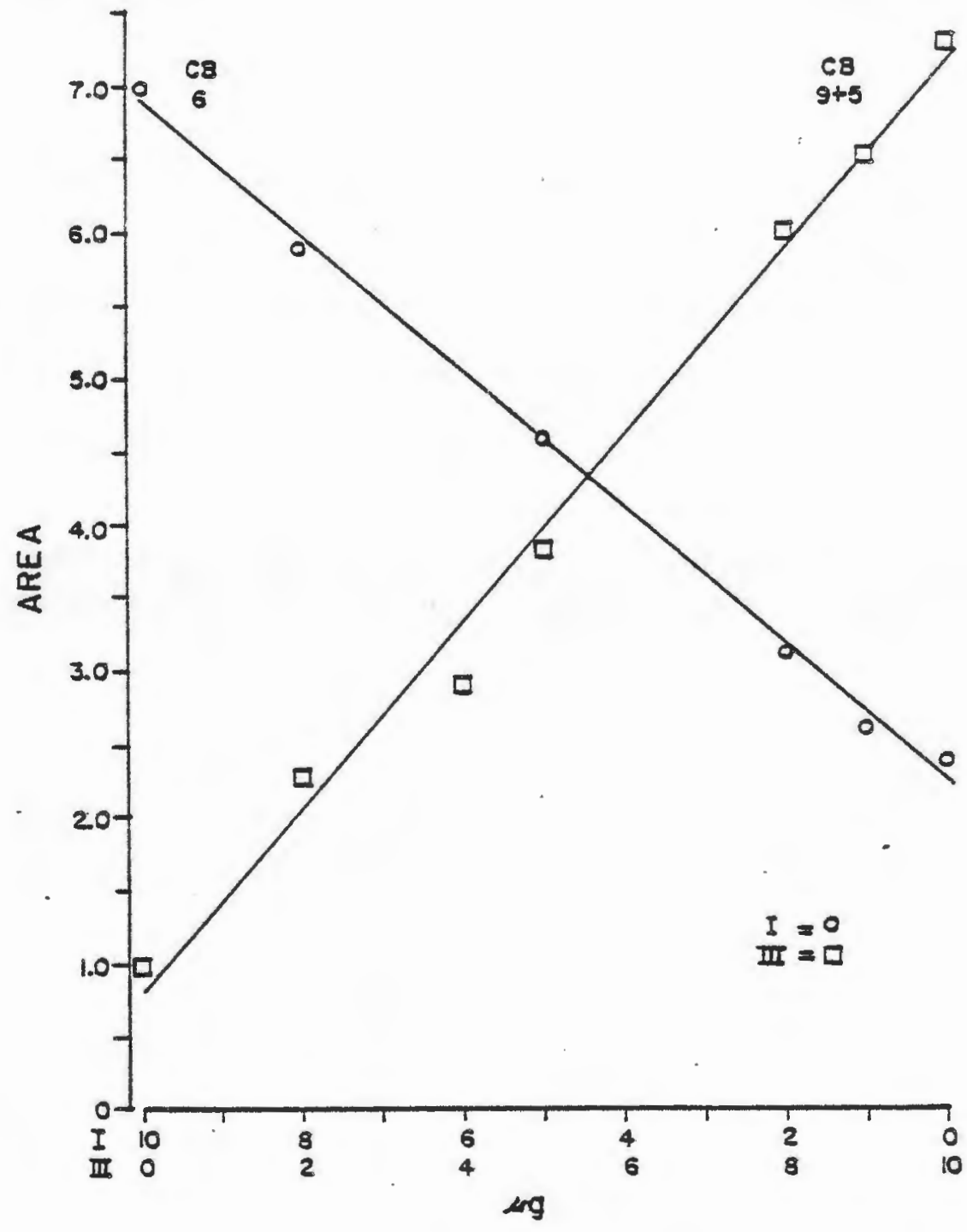

Fig. 18. An $x$ plot standard curve for amount of Type I and III collagen versus CB peptides peak area. The RFI $x \mathrm{~mm}$ for I-CB6 was used for quantitating Type I collagen and the RFI $\mathbf{x} \mathrm{mm}$ for III-CB9, 5 was used for quantitating Type III collagen. A total of $10 \mu \mathrm{g}$ of MDPF-CB collagen was applied on each gel. Both lines were determined by linear regression with a coefficient of determination greater than .95 for both lines. 
have varying degress of susceptibility to cleavage depending upon the adjacent amino acid. There is formation of homoserine-o serine or 0 -theonine in the peptide linkage (Scott and Veis, 1976). The cyanogen bromide method is not applicable for less than 108 type III collagen because of the closeness of the $C B$ peaks from type $I$ and III collagen. The cyanogen bromide method can be used for confimation of type III by $\alpha$ chain quantitation from the decrease of $Y$ and increase in $\alpha$ after reduction measured by MDPF-SDS-PAGE. 


\section{CONCLUSIONS}

1. The relative fluorescence of MDPF-collagen solution reaches a stable fluorescence within five minutes. A two to one ratio of MDPF to collagen concentration is optimum for maximum fluorescence by the coupling procedure described here.

2. MDPF slightly increases the mobility of collagen components in SDS-PAGE. The masking of the primary amines positive charge by MDPF is responsible for the more rapid migration towards the anode.

3. The area beneath the curve for MDPF labelled protein is independent of distance migrated.

4. Collagen can be quantitated from $10 \mathrm{ng}-10 \mathrm{\mu g}$. The relative fluorescent intensity for different collagen genetic types (i.e., I,II,III) are the same. 5. With reduction of type III collagen the decrease in higher molecular weight forms and $Y$ are accounted for by the increase in $\alpha$ and $\beta$ by fluorometric scanining but not by densiometric scanning.

6. A mixture of type I and type III collagen can also be quantitated by MDPF-collagen cyanogen bromide peptides. 7. For the quantitation of collagen in polyacrylamide gel the fluorescent method (MDPF-SDS-PAGE) has a number of advantages over the gel staining method: 
a) Bands can be observed during electrophoresis with a long wave UV lamp with quantitation immediately after electrophoresis

b) The quantitation of fluorescence has a variability of $\pm 6 \% \mathrm{SE}$.

c) Area does not change with distance migrated.

d) Fluorescent scanning technique has a wide range of linearity $10 \mathrm{ng}-10 \mathrm{\mu g}$ and a sensitivity for detection of $10^{-8} \mathrm{~g}$.

e) Gels can be analyzed in electrophoresis tubes. 


\section{REFERENCES}

Bailey, A.J., Bazin, S., Sims, T.J., LeLons, M., Nicoletis, C. and Delaney, A.: Characterization of collagen of human hypertropic and normal scars. Biochem. Biophys. Acta. 405: $412-421,1975$.

Bailey, A.J., Robins, S.P. and Balian, G.: Biological significance of the intermolecular cross-links of collagen. Nature (London) 251:105-109, 1974.

Barger, B.O., White, F.C., Pace, J.I., Kemper, D.I. and Ragland, W.L.: Estimation of molecular weight by polyacrylamide gel. electrophoresis using heat stable fluorophors. Anal. Biochem. 70:327-335, 1976.

Barnes, M.J., Morton, L.F. and Levene, C.I.: Synthesis of collagens types I and III by pig medial smooth muscle cells in culture. Biochem. Biophys. Res. Commun. 70:339-349, 1976.

Bennett, J. and Scott, K.J.: Quantitative staining of fraction I protein in polyacrylamide gels using coomassie brilliant blue. Anal. Biochem. 43:173-182 (1971).

Benya, P.D., Padilla, S.R. and Nimni, M.E.: The progeny of rabbit articular chondrocytes synthesize collagen types I and III and type I trimer but not type II. Verification by cyanogen bromide peptide analysis. Biochem. 16:865-872, 1977.

Bertolini, M.J., Tankersley, D.I. and Schroeder, D.D.: Staining and destaining polyacrylamide gels: a comparison of coomassie blue and fast green protein dyes. Anal. Biochem. 71: $6-13,1976$.

Böhlen, P., Stein, S., Dairman, W. and Undenfriend, S.: Flurometric assay of proteins in the nanogram range. Arch. Biochem. Biophys. 155:213-220, 1973.

Brownell, A.G. and Veis, A.: The intracellular location of glycosylation of hydroxylsine of collagen. Biochem. Biophys. Res. Commun. 63:371-377, 1975 .

Byers, P.H., Click, E.M., Harper, E. and Bornstein, P.: Interchain disulphide bonds in procollagen are located in a large, non-triple helical CoOH-terminal domain. Proc. Natl. Acad. Sci. U.S.A. 72:17-25, 1975.

Clark, C.C., Tomichek, E.A., Koszalka, T.R., Minor, R.R. and Kefalides, N.A.: The embronic rat parietal yolk sac. The role of the parietal endoderm in the biosynthesis of basement membrane collagen and glycoprotein in vitro. J. Biol. Chem. $\underline{250}: 5259-5267,1975$. 
Click, E.M. and Bornstein, P.: Isolation and characterization of the cyanogen bromide peptide from the $\alpha_{1}$ and $\alpha 2$ chains of human skin collagen. Biochemistry $\underline{9}: 4699-4706$, 1970.

Chung, E. and Miller, E.J.: Characterization of molecules with the chain composition [al(III) $]_{3}$ in human tissues. Science 183:1200-1201, 1974.

Eng, P.R. and Parkes, C.O.: SDS electrophoresis of fluorescamine-labeled proteins. Anal. Biochem. 59:323-325, 1974.

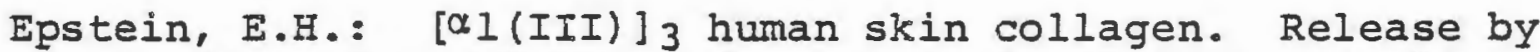
pepsin digestion and preponderance in fetal life. J. Biol. Chem. 24:9:3225-3231, 1974 .

Epstein, E.H. and Munderloh, N.H.: Isolation and characterization of CNBr peptide of human [ $\alpha I$ (III)] 3 collagen and tissue distribution of $[\alpha I(I)]_{2}$ and $[\alpha I \text { (III) }]_{3}$ collagens. J. Biol. Chem. 250:9304-9312, 1975 .

Fishbein, W.N.: Quantitative densitometry of 1-50. ug protein in acrylamide gel slabs with Coomassie blue. Anal. Biochem. $46: 388-401,1972$.

Fujii, T. and Kuhn, K.: Isolation and characterization of pepsin treated type III collagen from calf skin. Physiol. Chem. 356:1793-180I, 1975.

Furthmayr, H. and Timpl, R.: Characterization of collagen peptides by sodium dodecyl sulfate-polyacrylamide electrophoresis. Anal. Biochem. 41:510-516, 1971.

Gay, S., Baileisen, I., Remberger, K., Fietzek, P.P., Adelmann, B.C. and Kühn, K.: KIin Wschr. 53:899-902, 1975.

Goldberg, B., Taubman, M.B. and Radin, A.: Procollagen peptidase: its mode of action on the native substrate. Cell. $4: 45-50,1975$.

Goloberg, R.I. and Fuller, G.C.: Quantitation of collagen in polycrylamide gels by fluorescent scanning of MDPF labeled proteins: improvement over densiometric scanning of Coomassie blue stained gels. Anal. Biochem. in press.

Gorovsky, M.A., Carlson, K. and Rosenbaun, J.I.: Simple methods for quantitative densiotometry of polyacrylamide gels using fast green. Anal. Biochem. 35:359-370, 1970.

Hance, A.J. and Crystal, R.G.: Rigid controi of synthesis of collagen types I and III by cells in culture. Nature 268: $152-154,1977$. 
Jaffe, E.A., Minick, C.R., Adelman, B., Becker, C.G. and Nachman, R.: Synthesis of basement membrane collagen by cultured human endothelial cells. J. Exptl. Med. 144:209$255,1976$.

Rent, G., Gay, S., Inouze, T. and Popper, H.: Type I and III collagen in experimental liver injury. Gastroent. 71: 907-912, 1976 .

Kivirikko, R.I. and Prockop, D.J.: Partial purification and characterization of protocollagen lysine hydroxylase from chick embryos. Biochem. Biophys. Acta. 258:366-379, 1972.

Kivirikko, K.I. and Risteli, I.: Biosynthesis of collagen and its alterations and in pathological states. Med. Bio. 54:159-186, 1976 .

Kohn, R.R. and Hensse, S.: Abnormal collagen in culture fibroblast from human being.with diabetes mellitus. Biochem. Biophys. Res. Comm. 76:765-771, 1977.

Kuttan, R., Kaplan, S., Matoney, I. and Fuller, G.C.: Synthesis of type III collagen in synovial tissue of patients with arthritis and synovial cells grown in culture. $J$. Clin. Inv. in press.

Lapiere, C.M. and Nusgens, B.: Collagen pathology at the molecular level. In Biochemistry of Collagen. ed. by Ramachandran, G.N. and Reddi, A.H. Plenum Press, New York, 1976.

Lichtenstein, J.R., Bauer, E.A., Hoyt, R. and Wedner, H.J.: Immunologic characterization of the membrane-bound collagen in normal human fibroblasts: identification of a distinct membrane collagen. J. Exp. Med. 144:145-154, 1976.

Liotta, L.A., Rleinerman, J., Catanzaro, P. and Rynbrandt, D.: Degradation of basement membrane by murine tumor cells. J. Nat. Cancer Inst. 58:1427-1431, 1977.

Little, C.D., Church, R.I.; Miller, R.A. and Ruddle, F.H.: Procollagen and collagen produced by a tehatocorcinoma-derived cell line, TSD4:evidence for a new molecular form of collagen. Cell: 10:287-295, 1977.

McCullagh, K.A. and Balian, G.: Collagen characterization and cell transformation in human atherosclerosis. Nature (London) 258:73-75, 1976.

McCullagh, R.G. and Ehrhart, I.A.: Increased arterial collagen in experimental canine atherosclerosis. Atherosclerosis $19=13-28,1974$. 
Miller, A.: Molecular packing in collagen fibrils. In Biochemistry of Collagen. Ed. by Ramachandran, G.N. and Reddi, A.H. Plenum Press, New York, 1976.

Miller, E.J.: Biochemical characteristics and biological significance of the genetically-distinct collagens. Molec. \& Cell. Biochem. 13:165-192, 1976(a).

Miller, E.J.: Separation of collagen fractions on caxborymethyl cellulose. The Methodology of Connective Tissue Research. Ed. by David A. Hall. Joynson Bruvers LTD, oxford, $1976(\mathrm{~b})$.

Mueller, P.K., Lemmen, C., Gay, S. and Meigel, W.: Disturbance in the regulation of the type of collagen synthesis in osteogenesis imperfecta. Eur. J. Biochem. 59:97-104, 1975 .

Neville, D.M.: Molecular weight determination of protein dodecyl sulfate complex by gel electrophoresis in a discontinuous buffer system. J. Biol. Chem. 246:6328-6334, 1971.

Olsen, B.R., Berg, R.A., Rishida, Y. and Prochop, D.J.: Further characterization of embryonic tendon fibroblasts and the use of immunoferritin techniques to study collagen biosynthesis. J. Cell. Biol. 64:340-355, 1975.

Ooshima, A., Fuller, G.C., Cardinale, G., Spector, S. and Underfriend, S.: Increased collagen biosynthesis in blood vessels of hypertensive rats and its reversal by hypertensive agents. Proc. Natl. Acad. Sci. USA 71:3019-3023, 1974.

Pace, J.L., Kemper, D.I. and Ragland, W.I.: The relationship of molecular weight to electrophoretic mobility of fluorescamine-labeled proteins in polyacrylamide gels. Biochem. Biophys. Res. Comm. 57:482-487 (1974).

Piez, K.A.: Primary structure. In Biochemistry of Collagen. ed. Ramachandran, G.N. and Reddi, A.H. Plenum Press, N.Y., 1976.

Pope, I.M., Martin, G.R., Iichenstein, J.R., Penthinen, R., Gerson, B., Rowe, D.W. and McKusick, V.A.: Patients with Ehlers-Danlos syndrome type IV lack type III collagen. Proc. Natl. Acad. Sci. 72:1314-1316, 1975.

Prockop, D.J., Berg, R.A., Kivirikko, K.I. and Uitto, J.: Intracellular steps in the biosynthesis of collagen. In Biochemistry of Collagen. Ed. by Ramachandran, G.N., Reddi, A.H. Plenum Publ. Corp., N.Y., 1976 . 
Ramachandran, G.N. and Ramakrishnan, C.: Molecular structure. In Biochemistry of Collagen, ed. by Ramachandran, G.N. and Reddi, A.H. Plenus Press, N.Y., 1976.

Ross, R. and Gomset, J.A.: Atherosclerosis and the arterial smooth muscle cell. Science 180:1332-1339, 1973.

Rojkin., M. and Martinez-Palomo, A.: Increase in type I and type III collagen in human alcoholic liver chirrosis. Proc. Nat. Acad. Sci. 73:539-543, 1976.

Scott, D.M., Harwood, R., Grant, M.E. and Jackson, D.S.: Characterization of the major collagen species present in porcine aortal and the synthesis of their precursors by smooth muscle cells in culture. Connect. Tiss. Res. 5:7-13, 1977.

Scott, P.G., Tedser, A.G. and Veis, A.: Semequalitative determination of cyanogen bromide peptide of collagen in SDSpolyacrylamide gels. Anal. Biochem. 70:251-257, 1976.

Scott, P.G. and Veis, A.: The cyanogen bromide peptides of bovine soluble and insoluble collagen. Connect. Tiss. Res. 4: 107-129, 1976a.

Scott, P.G., Veis, A. and Mechanic: The identity of a cyanogen bromide fragment of bovine dentin collagen containing the site of an intermolecular crosslink. Biochemistry 15:3191$3197,1976 b$.

Smith, G.N., Thomas, F., Lensenmayer, and Newsome, D.A.: Synthesis of type II collagen in vitro by embryonic chick neral retina tissue. Proc. NatI. Acad. Sci. 73:4420-4425, 1976.

Svojtkova, E., Deyl, Z. and Adam, M.: Anomalies in the electrophoretic molecular weight determination of collagen denatured products. J. Chrom. 84:147-153, 1973.

Sykes, B.C.: The separation of two soft tissue collagens by covalent chromatography. Febs Let. 61:180-185, 1976.

Tanzer, M.I.: Cross-linking. In Biochemistry of Collagen. ed. by Ramachandran, G.N. and Reddi, A.H. Plenum Press, N.Y., 1976 .

Tanzer, M.I., Church, R.I., Yaeger, J.A., Wamplér, D.E. and Park, E.D.: Procollagen: intermediate forms containing several types of peptide chains and non-collagen peptide extension at the $\mathrm{NH}_{2}$ and $\mathrm{COOH}$ ends. Proc. Natl. Acad. Sci. USA $71: 3009-3013,1974$. 
Tanzer, M.L.: Cross-linking of collagen. Science 180:561-566, 1973.

Timpl, R.: Immunological studies oncollagen. In Biochemistry of Collagen. Ed. by Ramachandran, G.N. and Reddi, A.H. Plenum Press, N.Y., 1976.

Weber, L., Meigel, W.N. and Rauterberg, J.: SDS-polyacrylamide gel electrophoretic determination of type $I$ and type III collagen in small skin samples. Arch. Derm. Res. 258: 251-257, 1977 .

Weber, K. and Osborn, M-: The Reliability of Molecular Weight Determination by Dodecyl Sulfate-Polyacrylamide Gel Electrophoresis. J. Biol. Chem. 244:4406-4412, 1969.

Weigle, M., De Bernardo, S., Leimgruber, W., Cleeland, R. and Grunberg, E.P.: Fluorescent labeling of proteins. A new methodology. Biochem. Biophys. Res. Commun. 54:899896,1973 .

Weiss, J.B., Shuttleworth, C.A., Brown, R., Sedowfia, K., Baildam, A. and Hunter, J.A.: Occurrence of type III collagen in inflamed synovial membrane: a comparison between nonrhematoid, rhematoid and normal synovial collagen. Biochem. Biophys. Res. Comm. 65:907-912, 1975. 